\title{
An In Situ XAS Study of the Cobalt Rhenium Catalyst for Ammonia Synthesis
}

\author{
Karina Mathisen ${ }^{1} \cdot$ Karsten Granlund Kirste $^{1} \cdot$ Justin S. J. Hargreaves ${ }^{2} \cdot$ Said Laassiri $^{2} \cdot$ Kate McAulay $^{2}$. \\ Andrew R. McFarlane ${ }^{2} \cdot$ Nicholas A. Spencer $^{2}$
}

Published online: 12 February 2018

(c) The Author(s) 2018. This article is an open access publication

\begin{abstract}
A cobalt rhenium catalyst active for ammonia synthesis at $400{ }^{\circ} \mathrm{C}$ and ambient pressure was studied using in situ XAS to elucidate the reducibility and local environment of the two metals during reaction conditions. The ammonia reactivity is greatly affected by the gas mixture used in the pre-treatment step. Following $\mathrm{H}_{2} / \mathrm{Ar}$ pre-treatment, a subsequent 20 min induction period is also observed before ammonia production occurs whereas ammonia production commences immediately following comparable $\mathrm{H}_{2} / \mathrm{N}_{2}$ pre-treatment. In situ XAS at the Co K-edge and $\mathrm{Re}_{\mathrm{III}}$-edge show that cobalt initiates reduction, undergoing reduction between 225 and $300{ }^{\circ} \mathrm{C}$, whereas reduction of rhenium starts at $300{ }^{\circ} \mathrm{C}$. The reduction of rhenium is near complete below $400{ }^{\circ} \mathrm{C}$, as also confirmed by $\mathrm{H}_{2}$-TPR measurements. A synergistic co-metal effect is observed for the cobalt rhenium system, as complete reduction of both cobalt and rhenium independently requires higher temperatures. The phases present in the cobalt rhenium catalyst during ammonia production following both pre-treatments are largely bimetallic Co-Re phases, and also monometallic Co and Re phases. The presence of nitrogen during the reduction step strongly promotes mixing of the two metals, and the bimetallic $\mathrm{Co}-\mathrm{Re}$ phase is believed to be a pre-requisite for activity.
\end{abstract}

Keywords Ammonia $\cdot$ Cobalt $\cdot$ Rhenium $\cdot$ In situ XAS

\section{Introduction}

Since the development of the Haber Bosch Process at the beginning of the twentieth Century, considerable effort has been made to reduce the severity of the process by developing new efficient catalytic materials operational under milder reaction conditions [1-5]. The current industrial catalyst which is based on promoted iron is operated at high pressure (ca. 100-300 atm.) and moderate temperatures (ca.

Electronic supplementary material The online version of this article (https://doi.org/10.1007/s11244-018-0892-7) contains supplementary material, which is available to authorized users.

Karina Mathisen

karina.mathisen@ntnu.no

$\triangle$ Justin S. J. Hargreaves

Justin.Hargreaves@glasgow.ac.uk

1 Department of Chemistry, Norwegian University of Science and Technology (NTNU), Høgskoleringen 5, 7491 Trondheim, Norway

2 WestCHEM, School of Chemistry, University of Glasgow, Joseph Black Building, Glasgow G12 8QQ, UK
$400{ }^{\circ} \mathrm{C}$ ) to ensure acceptable industrial ammonia production rates [6]. Amongst the materials developed as alternatives to the iron based system, Re based catalysts display comparatively high catalytic activity [7]. The catalytic activity of such Re based catalysts was found only to be stabilized when cobalt was added as a promoter to the bulk Re (atomic ratio of 4:1 Re:Co), whereas rapid deactivation over time was observed in the case of the non-promoted system [8]. The stability of the cobalt rhenium phase was correlated in the literature to the formation of a stable active rhenium nitride phase upon the ammonolysis step employed in its preparation. Subsequently, more recent work from McAulay et al. [9] has demonstrated that highly active cobalt rhenium catalysts can be prepared without an ammonolysis stage. Interestingly, a pronounced influence of pre-treatment gas mixture was reported in the catalytic activity of this material with $75 \% \mathrm{H}_{2}$ in $\mathrm{N}_{2}$ leading to more active catalyst than when applying $75 \% \mathrm{H}_{2}$ in Ar. Furthermore, an induction period of 20 min was observed before the catalytic activity developed in the case of the $\mathrm{H}_{2}$ in $\mathrm{Ar}$ pre-treated catalyst [9]. Although, post-reaction analysis did not reveal any relevant structural changes in cobalt rhenium upon the different pre-treatments, 
subtle changes, not easily detected by classical characterization techniques, might be responsible for these differences.

In situ X-ray absorption spectroscopy (XAS) has been reported in the literature as an efficient tool for studying the rhenium cobalt catalyst used in the Fischer-Tropsch Process [10-15]. Since XAS is an element specific probe, information related to the local environment of each constituent, Co or Re, can be obtained in an independent manner [16]. The Near Edge (XANES) region is highly sensitive to local environment and oxidation state, meaning fingerprinting with carefully selected reference compounds can reveal initial information about the state of the elements involved. From the extended fine structure region (EXAFS) structural information, inaccessible by standard characterization techniques, can be obtained about the local environment (up to a distance of $4 \AA$ ) surrounding the absorbing atom. For instance rhenium promoted $\mathrm{Co} / \mathrm{Al}_{2} \mathrm{O}_{3}$ was studied via in situ EXAFS at the $\operatorname{Re} \mathrm{L}_{\mathrm{III}}(10535 \mathrm{eV})$ and Co K $(71676 \mathrm{eV})$ edges [17]. Analysis of both edges indicated that the Re was atomically distributed inside bulk Co particles. At the $\mathrm{Re} \mathrm{L}_{\mathrm{III}}$ edge an increased Re-Co interatomic distance was found (in comparison to a model based on DTF calculations by Bakken et al. [18]) and this was attributed to a distortion of the local Co environment for the Co particles which were in direct contact with Re particles. This distortion was only evident at the Re $\mathrm{L}_{\mathrm{III}}$ edge and was not found at the Co K-edge or by $\mathrm{XRD}$ analysis [19]. Bimetallic Re-Co interactions during the reduction of $\mathrm{Co}-\mathrm{Re} / \mathrm{Al}_{2} \mathrm{O}_{3}(2 \mathrm{wt} \% \mathrm{Co}$ and $4.6 \mathrm{wt} \% \mathrm{Re}$ ) were also studied by Rønning et al. [15]. Insight into the reduction behaviour of Re and Co was obtained using in situ EXAFS analysis. The reduction of rhenium was found to occur subsequently to the reduction of cobalt. The reduction process resulted in the formation of bimetallic Re-Co species with Re-Co distances found to be approximately $2.53 \AA$.

In this paper, the structural evolution of the cobalt rhenium system resulting from the different pre-treatments and during the induction period has been examined by in situ XAS using conditions mimicking ammonia synthesis conditions. Figures denoted by $\mathrm{S}$ within the text can be found in the Supplementary Information.

\section{Experimental}

\subsection{Cobalt Rhenium Synthesis and Preparation of References}

Cobalt rhenium was prepared by incipient wetness impregnation of $\mathrm{NH}_{4} \mathrm{ReO}_{4}$ (Sigma Aldrich, 99\%) with $\mathrm{Co}\left(\mathrm{NO}_{3}\right)_{2} \cdot 6 \mathrm{H}_{2} \mathrm{O}$ (Sigma Aldrich, 98\%) to yield a synthesis $\mathrm{Co} / \mathrm{Re}$ ratio of $1 / 4$, as previously described [9]. The sample was dried overnight and calcined in air at $700{ }^{\circ} \mathrm{C}$ for $3 \mathrm{~h}$. Inductively Coupled Plasma-Mass Spectroscopy (ICP-MS) elemental analysis was conducted using a High Resolution Inductively Coupled Plasma MS Element 2 from Thermo Scientific. The samples (10-20 mg) were decomposed by adding concentrated nitric acid $\left(\mathrm{HNO}_{3}, 1.5 \mathrm{ml}\right)$ and hydrofluoric acid (HF, $40 \mathrm{wt} \%, 0.6 \mathrm{~g})$. The resultant solution was diluted with deionized water until a total weight of $216.6 \mathrm{~g}$ was reached.

Nitrided cobalt $\left(\mathrm{CoN}_{\mathrm{x}}\right)$ was prepared by reaction of ammonia with $\mathrm{Co}_{3} \mathrm{O}_{4}$ at $700{ }^{\circ} \mathrm{C}$ for $2 \mathrm{~h}$. The temperature was increased from room temperature to $300{ }^{\circ} \mathrm{C}$ over $30 \mathrm{~min}$, after which it was increased to $450{ }^{\circ} \mathrm{C}$ at a rate of $0.7{ }^{\circ} \mathrm{C}$ $\mathrm{min}^{-1}$ and then up to $700{ }^{\circ} \mathrm{C}$ at a rate of $1.67{ }^{\circ} \mathrm{C} \mathrm{min}-1$. Nitrided rhenium $\left(\operatorname{ReN}_{\mathrm{x}}\right)$ was prepared by ammonolysis of $\mathrm{NH}_{4} \mathrm{ReO}_{4}$ (Sigma Aldrich, $99.5 \%$ ) at $350{ }^{\circ} \mathrm{C}$ for $2 \mathrm{~h}$. A temperature ramp rate of $5^{\circ} \mathrm{C} \mathrm{min}^{-1}$ was applied. Nitrided cobalt rhenium $\left(\mathrm{CoRe}_{\mathrm{y}} \mathrm{N}_{\mathrm{x}}\right)$ was prepared by ammonolysis of a cobalt rhenium oxide precursor, prepared as described above, at $700{ }^{\circ} \mathrm{C}$ for $3 \mathrm{~h}$. A temperature ramp rate of $5{ }^{\circ} \mathrm{C}$ $\min ^{-1}$ was applied.

\subsection{Denitridation}

The reactivity of cobalt rhenium was probed, using $0.3 \mathrm{~g}$ of catalyst, under an atmosphere of $75 \% \mathrm{H}_{2}$ in $\mathrm{Ar}$ (BOC, 99.98\%) at a total gas feed of $60 \mathrm{ml} \mathrm{min}^{-1}$. Prior to reaction, the cobalt rhenium material was activated under an atmosphere of $75 \% \mathrm{H}_{2}$ in $\mathrm{N}_{2}$ (BOC, 99.98\%) mixture at a total gas feed of $60 \mathrm{ml} \mathrm{min}^{-1}$ at $600{ }^{\circ} \mathrm{C}$ for $2 \mathrm{~h}$. Ammonia production applying a $60 \mathrm{ml} \mathrm{min}{ }^{-1}$ flow of $75 \% \mathrm{H}_{2}$ in $\mathrm{Ar}$ at $400{ }^{\circ} \mathrm{C}$ was determined by measurement of the decrease in conductivity of a $200 \mathrm{ml} 0.0018 \mathrm{M} \mathrm{H}_{2} \mathrm{SO}_{4}$ solution through which the reactor effluent stream was flowed.

\subsection{Temperature Programmed Reduction}

The reducibility of cobalt rhenium samples was studied by temperature programmed reduction (TPR). $40 \mathrm{mg}$ of sample was pre-treated under $5.0 \mathrm{vol} \% \mathrm{O}_{2}$ in He using a flow rate of $50 \mathrm{ml} \mathrm{min}{ }^{-1}$ at $600{ }^{\circ} \mathrm{C}$ for $2 \mathrm{~h}$, and then cooled down to ambient temperature. Thereafter, the TPR experiment was performed under a mixture of gases composed of $5.0 \mathrm{vol} \%$ $\mathrm{H}_{2}$ in He using a total gas feed of $50 \mathrm{ml} \mathrm{min}^{-1}$ with a temperature ramp rate of $5^{\circ} \mathrm{C} \mathrm{min}^{-1}$.

\subsection{XAS Data Collection}

Cobalt K-edge and rhenium $\mathrm{L}_{\mathrm{III}}$-edge XAS data was collected in transmission mode at the Swiss-Norwegian Beamlines (SNBL, BM1B) at the European Synchrotron Radiation Facility (ESRF). The data was collected in the 16-bunch filling mode, providing a maximum current of $90 \mathrm{~mA}$. A bending magnet collects the white beam from the storage ring to the beamline. BM01B is equipped with a $\mathrm{Si}(111)$ 
double crystal monochromator for EXAFS data collection. The incident and transmitted intensities $\left(\mathrm{I}_{0}\right.$ and $\left.\mathrm{I}_{\mathrm{t}}+\mathrm{I}_{2}\right)$ were detected with ion chambers filled with, $\mathrm{I}_{0}(17 \mathrm{~cm}) 50 \%$ $\mathrm{N}_{2}+50 \% \mathrm{He}$, and $\mathrm{I}_{\mathrm{t}}$ and $\mathrm{I}_{2}(30 \mathrm{~cm})$ with $85 \% \mathrm{~N}_{2}+15 \%$ $\mathrm{Ar}$ at the cobalt edge. Post-ammonolysis samples $\left(\mathrm{CoN}_{\mathrm{x}}\right.$, $\mathrm{ReN}_{\mathrm{x}}$ and $\left.\mathrm{CoReN}_{\mathrm{x}}\right)$, cobalt references $\left(\mathrm{CoO}, \mathrm{Co}_{3} \mathrm{O}_{4}\right)$ and rhenium references $\left(\mathrm{ReO}_{3}, \mathrm{KReO}_{4}\right.$ and $\left.\mathrm{NH}_{4} \mathrm{ReO}_{4}\right)$ placed in aluminium sample holders were also collected ex situ and were mixed with boron nitride for optimum absorption. The cobalt XAS data were measured in continuous step scan from 7600 to $8300 \mathrm{eV}$ with a step size of $0.5 \mathrm{eV}$ and counting time $300 \mathrm{~ms}$. The rhenium $\mathrm{L}_{\mathrm{III}}$-edge data was collected in transmission mode, using ion chambers fillings $100 \% \mathrm{~N}_{2}$ $\left(\mathrm{I}_{0}, 17 \mathrm{~cm}\right), 50 \% \mathrm{~N}_{2}+50 \% \operatorname{Ar}\left(\mathrm{I}_{\mathrm{t}}\right.$ and $\left.\mathrm{I}_{2}, 30 \mathrm{~cm}\right)$. Step scans were collected between 10,350 and $11,800 \mathrm{eV}$, with a step size of $0.5 \mathrm{eV}$ and counting time $200 \mathrm{~ms}$.

For all in situ measurements, great care was taken to ensure that similar conditions were applied for both edges and hence sample weight, cell thickness and gas flow were kept constant. The cobalt rhenium catalyst was mixed with boron nitride, pressed into wafers and sieved. Sieved samples (above $375 \mu \mathrm{m}$ ) were then placed inside $0.9 \mathrm{~mm}$ quartz capillaries with quartz wool on either side. The capillary was heated by a blower placed directly under the sample, and the exhaust was continuously sampled using a Tristar Mass spectrometer.

Samples were studied using two protocols with pre-treatments either in $75 \% \mathrm{H}_{2}$ in $\mathrm{Ar}$ or $75 \% \mathrm{H}_{2}$ in $\mathrm{N}_{2}$ at $600{ }^{\circ} \mathrm{C}$ for $2 \mathrm{~h}$ using a $10{ }^{\circ} \mathrm{C} \mathrm{min}^{-1}$ temperature ramp rate with a total gas flowrate of $10 \mathrm{ml} \mathrm{min}^{-1}$. EXAFS step scans were collected continuously following the protocol shown in Figure S.1 with XRD patterns being collected at the end points. After the pre-treatment, samples were cooled to $400{ }^{\circ} \mathrm{C}$ and the reaction gas was switched to $75 \% \mathrm{H}_{2}$ in $\mathrm{N}_{2}$. EXAFS step scans were collected continuously. A setup with pneumatic switching valves and a secondary by-pass line was employed to prevent gas build-up during switching between gases.

\subsection{XAS Data Refinements}

The XAS data was binned (edge region -30 to $50 \mathrm{eV}$; pre-edge grid $10 \mathrm{eV}$; XANES grid $0.5 \mathrm{eV}$; EXAFS grid $0.05 \AA^{-1}$ ) and background subtracted, and the EXAFS part of the spectrum extracted to yield the $\chi_{i}^{\exp }(\mathrm{k})$ using Athena software from the IFFEFITT package. The XANES spectra were normalised from 30 to $150 \mathrm{eV}$ above the edge, while the EXAFS spectra were normalised from $150 \mathrm{eV}$ to the end point [20]. The data were carefully deglitched and truncated at the end of the EXAFS spectra when needed. The smooth background $\mu_{0}(E)$ was checked and corrected to achieve the maximum overlap with total absorption $\mu(\mathrm{E})$. Athena uses the Autobk algorithm to determine the background and normalise $\mu(E)$ data. Edge step normalisation was used, meaning that the difference between $\mu(E)$ and $\mu_{0}(E)$ was divided by an estimation of $\mu_{0}\left(\mathrm{E}_{0}\right)$. A line was regressed to the data in the region below the edge and subtracted from the data. A quadratic polynomial was then regressed to the data above the edge and extrapolated back to $\mathrm{E}_{0}[20]$. For cobalt the threshold energy $\left(\mathrm{E}_{0}\right)$ was set to be at the mid-point $(0.5)$ of the normalised absorption edge step ensuring it was chosen after any pre-edge or shoulder features. For rhenium samples $\mathrm{E}_{0}$ was determined to be the first inflection point in the first derivative spectra, as there are no pre-edges or shoulder features. All XANES spectra are energy corrected against the corresponding reference foil $(\mathrm{Co}=7709 \mathrm{eV}$, $\operatorname{Re}=10,535 \mathrm{eV})$

XANES is invaluable for distinguishing between valence states of transition metals and is highly sensitive towards changes in the electronic states and or the local environment. At every stage of the process, attempts were made to fit the experimental spectra to reference compounds, including corresponding foils, using the linear combination feature in the Athena package [20]. The normalised data were fitted from $-20 \mathrm{eV}$ below the edge and $60 \mathrm{eV}$ above the edge, allowing also the $\mathrm{E}_{0}$ value to be fitted, due to the ambiguity in selecting this value resulting from pre-edge features. All fits with unreasonable $\Delta \mathrm{E}_{0}$ values $( \pm 2.5 \mathrm{eV})$ were excluded. The maximum number of standards was set to three and the most relevant were chosen on the basis of the statistical goodness of fit.

EXAFS least-squares refinements were carried out using DL-EXCURV [21], which conducts the curve fitting of the theoretical $\chi^{\text {th }}(k)$ to the experimental $\chi^{\exp }(k)$ using the curved wave theory. The fit parameter reported for each refinement procedure is given by the statistical R-factor, defined as:

$R=\sum_{i}^{N}\left[\frac{1}{\sigma_{i}}\left(\left|\chi_{i}^{\exp }(k)-\chi_{i}^{\text {th }}(k)\right|\right)\right] \times 100 \%$

$\mathrm{Ab}$ initio phase shifts for both edges were also calculated within DL-EXCURV and verified using reference compounds. The amplitude reduction factor (AFAC) was extracted from the following reference compounds: $\mathrm{Co}_{3} \mathrm{O}_{4}$ and $\mathrm{NH}_{4} \mathrm{ReO}_{4}$ for the oxidized cobalt rhenium phase, while Co-foil and Re-foil were used for the reduced phase. The least-squares refinements were carried out in typical wave number k range $2-8.5 \AA^{-1}$ for cobalt and $\mathrm{k}$ range $3.5-9.5 \AA^{-1}$ for rhenium using a $\mathrm{k}^{3}$ weighting scheme.

\section{Results}

\subsection{Cobalt Rhenium Starting Material}

The original catalyst was labelled according to the original synthesis molar ratio between the cobalt and rhenium 
$\left.(\mathrm{CoRe})_{4}\right)$. However, in order to elucidate the real composition of the material ICP-MS was performed and such analysis revealed the actual molar composition to be $\mathrm{CoRe}_{1.6}$. The loss of rhenium from the sample may be attributed to volatilization of rhenium during the calcination stage at $700{ }^{\circ} \mathrm{C}$ in air prior to reaction. From here on in within this manuscript the cobalt rhenium catalyst will be labelled as $\mathrm{CoRe}_{1.6}$.

Figure 1 shows the Co K-edge and $\mathrm{Re} \mathrm{L}_{\mathrm{III}}$-edge normalised XANES of the $\mathrm{CoRe}_{1.6}$ starting material compared to reference compounds. The fresh $\mathrm{CoRe}_{1.6}$ does not show similarities to the oxides and instead the local cobalt surrounding is more comparable to the cobalt phosphate reference. Comparing $\mathrm{E}_{0}$ values, it is clear cobalt is present as a $\mathrm{Co}(\mathrm{III}) / \mathrm{Co}(\mathrm{II})$ mixture in the fresh catalyst prior to pretreatment. The XANES (Fig. 1) of the $\mathrm{CoRe}_{1.6}$ starting material resembles strongly the $\mathrm{NH}_{4} \mathrm{ReO}_{4}$ reference compound in also exhibiting similar absorption edge values to the $\operatorname{Re}(\mathrm{VII})$ references.

The EXAFS (Figure S.2) further confirms the above as refinements show an average coordination of four $\mathrm{Co}-\mathrm{O}$ pairs at $1.96 \AA$. EXAFS refinements of the fresh $\mathrm{CoRe}_{1.6}$ yield 3.4 Re-O absorption pairs at $1.70 \AA$ which is slightly shorter than those previously reported for tetrahedrally coordinated $\mathrm{ReO}_{4}{ }^{-}$(1.74 $\AA$ in $\mathrm{Bi} / \mathrm{Re} / \mathrm{O}$ compounds), and longer than the $\mathrm{Re}=\mathrm{O}$ double bonds reported from $\mathrm{X}$-ray diffraction of organo-rhenium (VII) oxides (1.67 $\AA$ ) [22]. By comparison the octahedral $\mathrm{Re}-\mathrm{O}_{\mathrm{Oh}}$ bond lengths are typically found at $1.89 \AA$ [23]. A second Re-O shell with a multiplicity of 3 is found at $2.15 \AA$, which appears to be too long to be octahedrally coordinated $\mathrm{ReO}_{6}{ }^{5-}$. However similar $\mathrm{Re}-\mathrm{O}$ bonds are also reported in the EXAFS studies of the oxides of Re/ Bi mentioned above [23]. Hence it can be concluded that both cobalt and rhenium are present in a highly oxidised state in $\mathrm{CoRe}_{1.6}$ prior to pre-treatment (Table 1).

\subsection{Denitridation}

To obtain a first indication of the role of pre-treatment in the possible formation of an active $\operatorname{CoRe}_{\mathrm{y}} \mathrm{N}_{\mathrm{x}}$ nitride phase during the induction time, denitridation of $\mathrm{N}_{2} / \mathrm{H}_{2}$ pretreated $\mathrm{CoRe}_{1.6}$ was undertaken using $\mathrm{H}_{2} /$ Ar. Pre-treatment was undertaken using $75 \% \mathrm{H}_{2}$ in $\mathrm{N}_{2}$ at $600{ }^{\circ} \mathrm{C}$ for $2 \mathrm{~h}$. The subsequent $\mathrm{H}_{2} / \mathrm{Ar}$ reaction profile, presented in Figure S.3, displayed an overall drop in conductivity of $42 \mu \mathrm{S} \mathrm{cm} \mathrm{cm}^{-1}$ which corresponded to a total ammonia production of $\sim 35$ $\mu$ moles of ammonia over 200 min of reaction, after which no further ammonia production was observed. Table 2 displays observed rates of ammonia production for selected nitrides
Fig. 1 Normalised XANES for $\mathrm{CoRe}_{1.6}$ compared to reference compounds Co K-edge (left) and Re L-III edge (right)
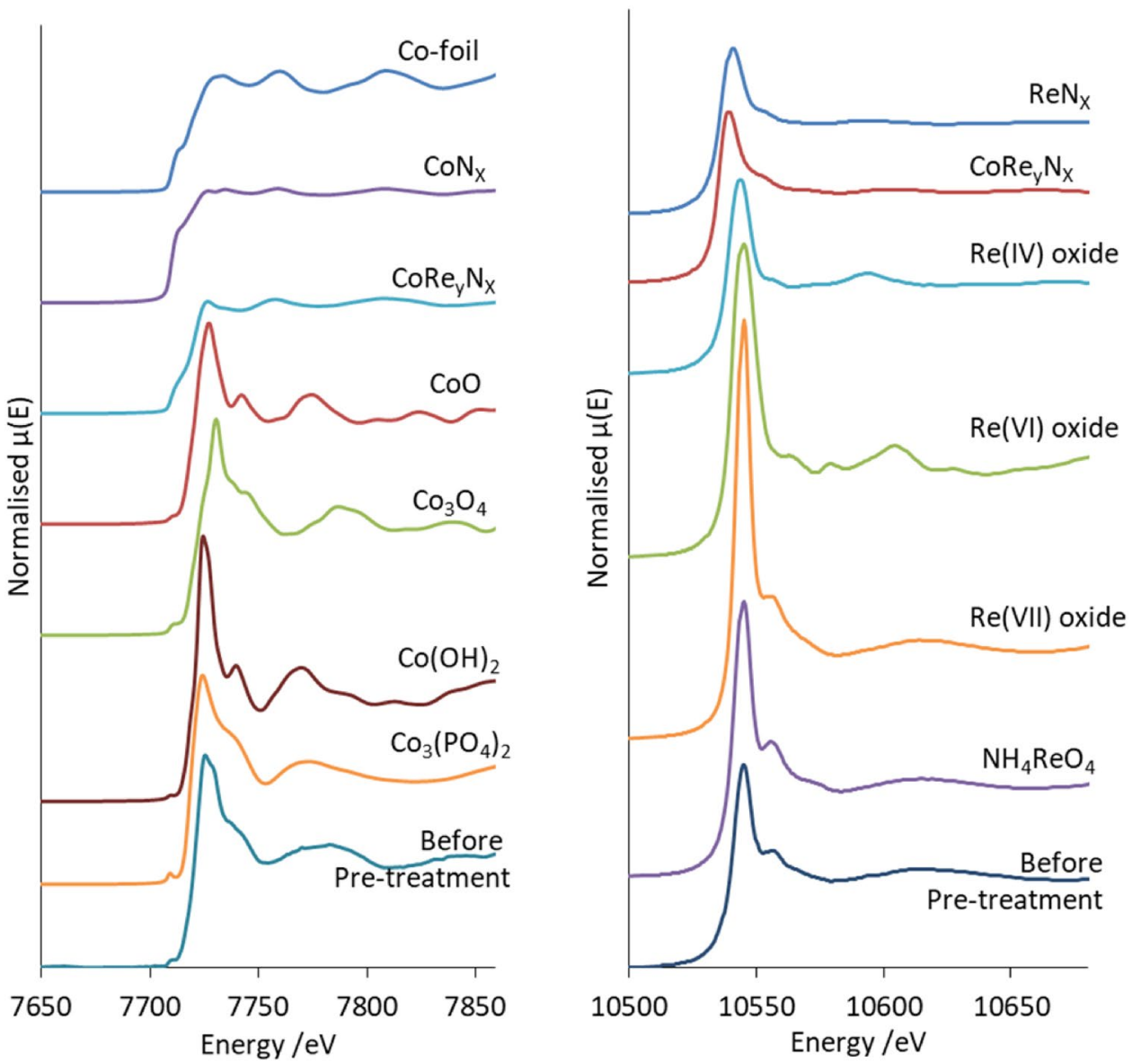
Table 1 Results from the least squares EXAFS analysis a at Re L-III-edge and Co K-edge for fresh CoRe4 (AFAC transferred from $\mathrm{Co}_{3} \mathrm{O}_{4}=0.66$ and $\mathrm{NH}_{4} \mathrm{ReO}_{4}=0.67$ ) and reference compounds $\operatorname{CoRe}_{\mathrm{y}} \mathrm{N}_{\mathrm{x}}$, $\mathrm{CoN}_{\mathrm{X}}$ and $\mathrm{ReN}_{\mathrm{x}}$ prepared by ammonolysis (AFAC transferred from Co-foil $=0.79$ and Re-foil $=0.8$ )

\begin{tabular}{llllllll}
\hline Sample & Shell & $\mathrm{N}$ & $\mathrm{R}(\AA)$ & $2 \sigma^{2}\left(\AA^{2}\right)$ & $\mathrm{EF}(\mathrm{eV})$ & $\mathrm{R}(\%)$ & $\Delta \mathrm{k}$ \\
\hline $\mathrm{CoRe}_{1.6}$ & $\mathrm{Co}-\mathrm{O}$ & $4(1)$ & $1.96(2)$ & $0.003(9)$ & $-2(2)$ & 58 & $2-8$ \\
& $\mathrm{Re}-\mathrm{O}$ & $3.4(3)$ & $1.704(7)$ & $0.003(1)$ & $-6(2)$ & 28 & $2-13$ \\
& $\mathrm{Re}-\mathrm{O}$ & $3(1)$ & $2.15(2)$ & $0.02(1)$ & & & \\
$\mathrm{CoRe}_{\mathrm{y}} \mathrm{N}_{\mathrm{x}}$ & $\mathrm{Co}-\mathrm{Co}$ & $4.6(7)$ & $2.468(6)$ & $0.018(3)$ & $-5.0(9)$ & 29 & $2-10$ \\
& $\mathrm{Co}-\mathrm{Re}$ & $2.0(8)$ & $2.66(1)$ & $0.011(7)$ & & & \\
$\mathrm{CoRe}_{\mathrm{y}} \mathrm{N}_{\mathrm{x}}$ & $\mathrm{Re}-\mathrm{N}$ & $0.4(2)$ & $1.76(3)$ & $0.01(1)$ & $-6(1)$ & 16 & $3.5-9.5$ \\
& $\mathrm{Re}-\mathrm{Co}$ & $3.0(5)$ & $2.57(1)$ & $0.022(3)$ & & & \\
& $\mathrm{Re}-\mathrm{Re}$ & $3.1(8)$ & $2.650(7)$ & $0.018(5)$ & & & \\
$\mathrm{CoN}_{\mathrm{x}}$ & $\mathrm{Co}-\mathrm{Co}$ & $4.0(8)$ & $2.50(1)$ & $0.013(3)$ & $-8(2)$ & 43 & $2-11$ \\
$\operatorname{ReN}_{\mathrm{x}}$ & $\mathrm{Re}-\mathrm{N}$ & $0.6(5)$ & $1.79(3)$ & $0.014(18)$ & $3(2)$ & 47 & $3.5-9$ \\
& $\mathrm{Re}-\mathrm{Re}$ & $7(2)$ & $2.67(2)$ & $0.032(8)$ & & & \\
$\mathrm{Co}^{*}$-foil & $\mathrm{Co}-\mathrm{Co}$ & 12 & $2.496(7)$ & $0.0132(8)$ & $-16(1)$ & 33 & $2-12$ \\
\hline
\end{tabular}

${ }^{a}$ The EXAFS refinements give information about multiplicity $(\mathrm{N})$, bonding distance $(\mathrm{R})$ and thermal vibration (Debye-Waller factor, $2 \sigma^{2}$ ). $E_{F}$ is the refined correction of Fermi energy in vacuum, compared to $E_{0}$. The standard deviation in the last significant digit as calculated by DL-excurv is given in parentheses. The deviation for $2 \sigma^{2}$ is $\pm 20 \%$. The Fit index is defined as FI $=\sigma_{i}\left(1 / \sigma_{i}\right)[\operatorname{Exp}(\mathrm{i})-\text { Theory (i) }]^{2}$. The statistical $\mathrm{R}$-factor is defined as $\mathrm{R}=\sigma_{\mathrm{i}}^{\mathrm{N}}\left[1 / \sigma_{i}\left(\left|\chi_{\mathrm{i}}^{\exp }(k)-\chi_{\mathrm{i}}^{\text {th }}(k)\right|\right)\right] \times 100 \%$ and gives indication of the quality of fit in k-space
Table 2 Overview of ammonia synthesis rates for selected nitrides compared to denitridation of cobalt rhenium

\begin{tabular}{lllll}
\hline Materials & Pre-treatment & $\begin{array}{l}\text { Reaction } \\
\text { conditions }\end{array}$ & $\begin{array}{l}\text { Rate }(\mu \mathrm{mol} \\
\left.\mathrm{g}^{-1} \mathrm{~h}^{-1}\right)\end{array}$ & Reference \\
\hline $\mathrm{Co}_{3} \mathrm{Mo}_{3} \mathrm{~N}$ & $\mathrm{H}_{2} / \mathrm{N}_{2}$ & $\mathrm{H}_{2} / \mathrm{N}_{2}$ & 652 & {$[4]$} \\
$\mathrm{Ni}_{2} \mathrm{Mo}_{3} \mathrm{~N}$ & $\mathrm{H}_{2} / \mathrm{N}_{2}$ & $\mathrm{H}_{2} / \mathrm{N}_{2}$ & 400 & {$[1]$} \\
$\mathrm{CoRe}_{4}$ & $\mathrm{H}_{2} / \mathrm{N}_{2}$ & $\mathrm{H}_{2} / \mathrm{N}_{2}$ & 943 & {$[9]$} \\
$\mathrm{CoRe}_{4}$ & $\mathrm{H}_{2} / \mathrm{Ar}$ & $\mathrm{H}_{2} / \mathrm{N}_{2}$ & 844 & {$[9]$} \\
$\mathrm{CoRe}_{1.6}$ & $\mathrm{H}_{2} / \mathrm{N}_{2}$ & $\mathrm{H}_{2} / \mathrm{Ar}$ & $\mathrm{a}$ & This paper \\
\hline
\end{tabular}

${ }^{\mathrm{a}}$ Rate not determined, deactivation after $2 \mathrm{~h}$ of reaction

and also the equivalent cobalt rhenium material previously reported (which is denoted as $\mathrm{CoRe}_{4}$, representing its synthesis ratio) under comparable reaction conditions $\left(400{ }^{\circ} \mathrm{C}\right.$, ambient pressure, $75 \% \mathrm{H}_{2}$ in $\mathrm{N}_{2}$ ). The low amount of ammonia generated in the absence of dinitrogen gas feed suggests a very low content of $\mathrm{N}$ being stored within the $\mathrm{CoRe}_{1.6}$ system, and possibly results from residual $\mathrm{N}$ stored on the surface.

\subsection{Reducibility of the Cobalt Rhenium System}

The active form of the cobalt rhenium system is typically obtained after reduction during the pre-treatment step at high temperature. The reducibility of $\mathrm{CoRe}_{1.6}$ and $\mathrm{Co}_{2} \mathrm{O}_{3}$ was evaluated using $\mathrm{H}_{2}$ TPR (Fig. 2). The reduction of $\mathrm{Co}_{2} \mathrm{O}_{3}$ started at a temperature as low as $200{ }^{\circ} \mathrm{C}$ and was characterized by two reduction steps. A small peak around

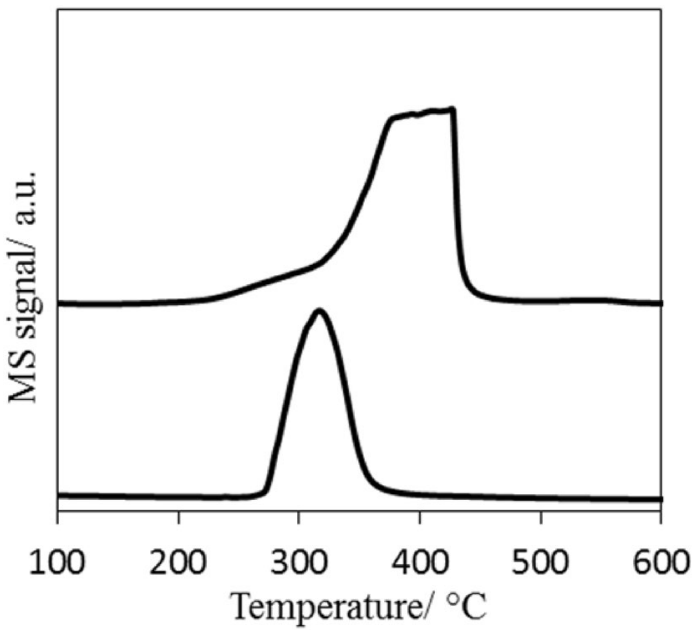

Fig. 2 Temperature programmed reduction (TPR) profiles of $\mathrm{CoRe}_{1.6}$ catalyst (lower profile) and $\mathrm{Co}_{2} \mathrm{O}_{3}$ (upper profile) under $\mathrm{H}_{2}$ flow

$230{ }^{\circ} \mathrm{C}$ can be observed which has been assigned in the literature to the reduction of $\mathrm{Co}^{3+}$ to $\mathrm{Co}^{2+}$ with the second peak occurring at higher temperature being attributed to the reduction of $\mathrm{Co}^{2+}$ to $\mathrm{Co}^{0}[24,25]$. The reduction profile of $\mathrm{CoRe}_{1.6}$ started at slightly higher temperature than the $\mathrm{Co}_{2} \mathrm{O}_{3}$ and was characterized by a single reduction step with a maximum located at $325{ }^{\circ} \mathrm{C}$. Hydrogen spillover from rhenium to cobalt oxide is widely accepted to promote the reduction of cobalt oxide which could explain the profile reduction of the $\mathrm{CoRe}_{1.6}[26,27]$. 
3.4 Effect of Different Pre-treatments; $\mathrm{H}_{2} / \mathrm{Ar}$ or $\mathrm{H}_{2} /$ $\mathrm{N}_{2}$

Selected normalised XANES (at $150{ }^{\circ} \mathrm{C}$ intervals, including relevant changes) of $\mathrm{CoRe}_{1.6}$ during pre-treatment in $75 \% \mathrm{H}_{2}$ in $\mathrm{N}_{2}$ and $75 \% \mathrm{H}_{2}$ in Ar from ambient temperature to $600{ }^{\circ} \mathrm{C}$ are shown in Fig. 3. The figure also presents the reduction profiles determined from linear combination of all XANES spectra. The $\mathrm{Co}$ III/II $\rightarrow \mathrm{Co}^{0}$ reduction occurs quite steeply, is initiated around $200{ }^{\circ} \mathrm{C}$, and clearly occurs before the reduction of $\mathrm{Re}^{\mathrm{VII}} \rightarrow \mathrm{Re}^{0}$, which starts at $300{ }^{\circ} \mathrm{C}$ for both pre-treatments as seen in Fig. 3. The starting point for the first reduction step for cobalt is somewhat lower for the $\mathrm{H}_{2} / \mathrm{Ar}$ pre-treatment. Typically complete reduction of rhenium requires much higher temperatures [28], hence these results suggest a cooperative effect between rhenium
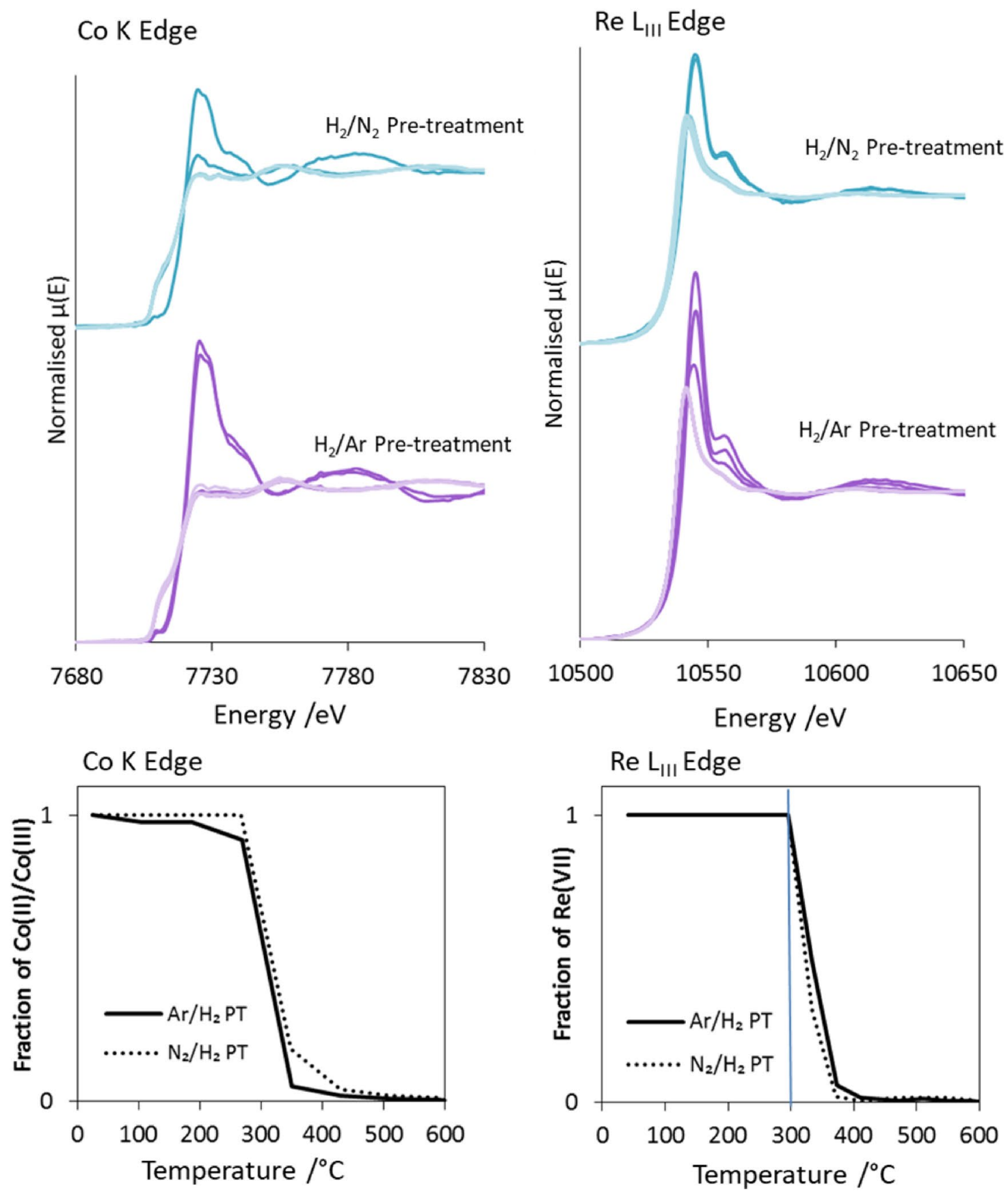

Fig. 3 Selected normalized XANES $\left(150{ }^{\circ} \mathrm{C}\right.$ intervals) during pre-treatments in $\mathrm{H}_{2} / \mathrm{Ar}$ and $\mathrm{H}_{2} / \mathrm{N}_{2}$ XANES for Co K-edge (top left) and Re $\mathrm{L}_{\mathrm{III}}$-edge (top right), and reduction profiles from linear combination of all normalized (30-150 eV) XANES in Athena (bottom) 
and cobalt, similar to the hydrogen spillover effect which has been reported for the Pt-Re system [29]. Both elements are reduced to the metallic state between 500 and $600{ }^{\circ} \mathrm{C}$. Other studies have also suggested the role of rhenium being to be the promotion of reduction of cobalt [15]. However, in the current study it is clear that cobalt initiates reduction of rhenium in the $\mathrm{CoRe}_{1.6}$ during both $\mathrm{H}_{2} / \mathrm{Ar}$ and $\mathrm{H}_{2} /$ $\mathrm{N}_{2}$ pre-treatments.

The normalised XANES of $\mathrm{CoRe}_{1.6}$ after the two pretreatments compared to references at the Co K-edge and Re $\mathrm{L}_{\mathrm{III}}$-edge are shown in Figs. 4 and 5 respectively. Both the shape of the XANES and the obtained $\mathrm{E}_{0}$ values confirm that the metals are present in the metallic state, however the cobalt data show two small features in the white line region (Fig. 4), whereas the cobalt foil shows one broad feature. These two smaller white line features are also reported in the cobalt XANES for the $\mathrm{PtCo} / \mathrm{Al}_{2} \mathrm{O}_{3}$ system after in situ $\mathrm{H}_{2}$ reduction, hence it would seem indicative of bimetallic Co-M interaction [30]. We cannot rule out re-oxidation in air of the post-ammonolysis samples as they were collected ex situ. The normalised rhenium XANES for the $\mathrm{CoRe}_{1.6}$ clearly appear at a lower $\mathrm{E}_{0}$ value also displaying a lower white line intensity (Fig. 4) when compared to $\operatorname{CoRe}_{y} \mathrm{~N}_{\mathrm{x}}$ and $\mathrm{ReN}_{\mathrm{x}}$ prepared by ammonolysis. This would confirm that rhenium in $\mathrm{CoRe}_{1.6}$ is fully reduced, whereas rhenium is partially re-oxidised in the post-ammonolysis references. There are clear similarities between the features observed in the XANES independent of pre-treatment for both edges, indicating that there are largely similar local metal surroundings at this point.

For the EXAFS analysis, attention was directed towards analysis of the structure of the cobalt rhenium phase and more precisely the mixing and bimetallic nature of the material during the pre-treatment and ammonia synthesis. The degree of bimetallic mixing is obtained by comparing the obtained average coordination of the first absorption shell which for the cobalt edge will comprise Co-Co and/or $\mathrm{Co}-\mathrm{Re}$, and similarly Re-Re and/or Re-Co at the rhenium edge. As EXAFS sees sums of contributions both absorption pairs will be present on respective edges if the material consists of a mixture of mono- and bimetallic phases. However, as these shells exhibit different bond distances the contributions should be resolved in EXAFS refinements. In a bimetallic system the degree of mixing is often best obtained from the minority element, which in our case is Co [31]. This can be exemplified by the following relationship $\mathrm{C}_{\mathrm{Re}} \times \mathrm{N}_{\mathrm{Re}-\mathrm{Co}}=\mathrm{C}_{\mathrm{Co}} \times \mathrm{N}_{\mathrm{Co}-\mathrm{Re}}$, where $\mathrm{C}_{\mathrm{Re}}$ and $\mathrm{C}_{\mathrm{Co}}$ are the concentrations of each metal, which means that heteroatomic
Fig. 4 Normalised XANES for $\mathrm{CoRe}_{1.6}$ during ammonia synthesis compared to reference compounds for Co K-edge for $\mathrm{H}_{2} / \mathrm{N}_{2}$ pre-treated (left) and $\mathrm{H}_{2} /$ Ar pre-treated (right)

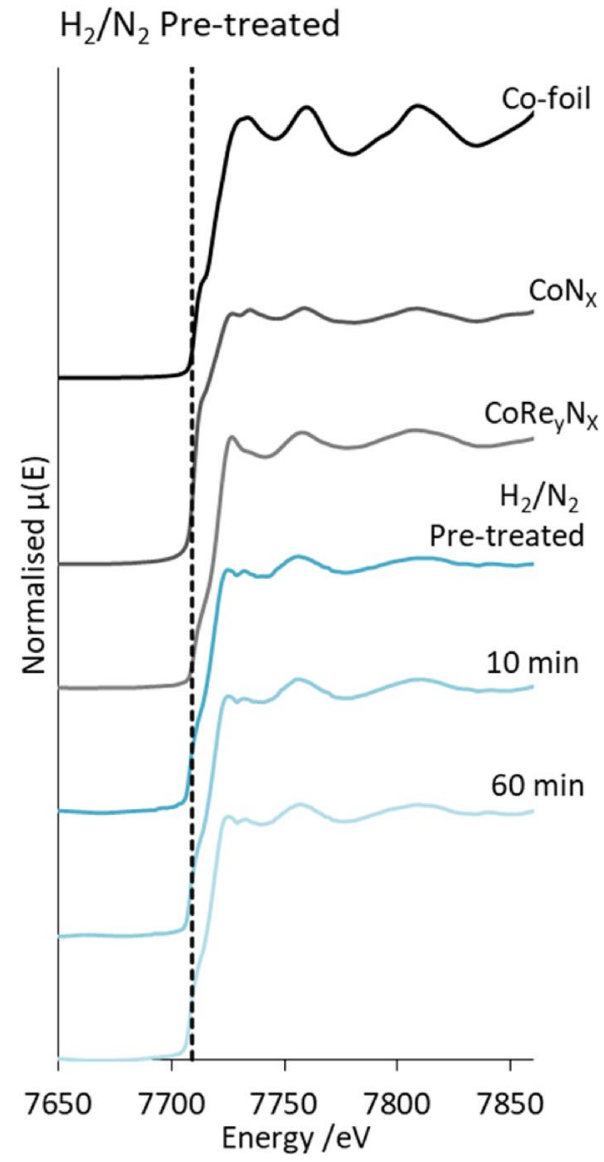

$\mathrm{H}_{2} /$ Ar Pre-treated

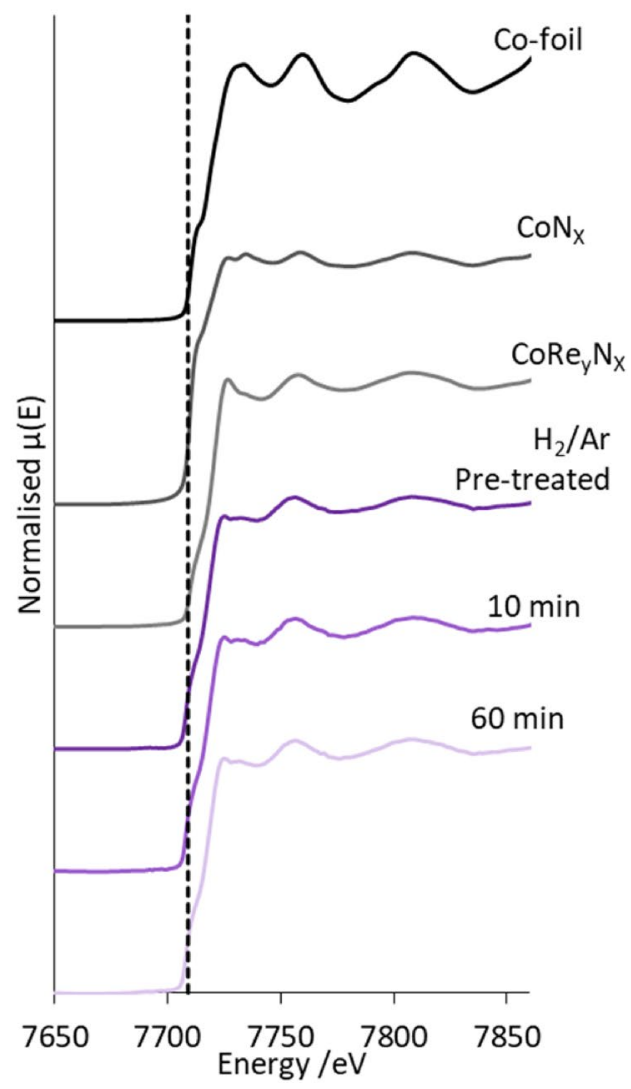


Fig. 5 Normalised XANES for $\mathrm{CoRe}_{1.6}$ during ammonia synthesis compared to reference compounds for Re L-III edge for $\mathrm{H}_{2} / \mathrm{N}_{2}$ pre-treated (left) and $\mathrm{H}_{2} /$ Ar pre-treated (right)

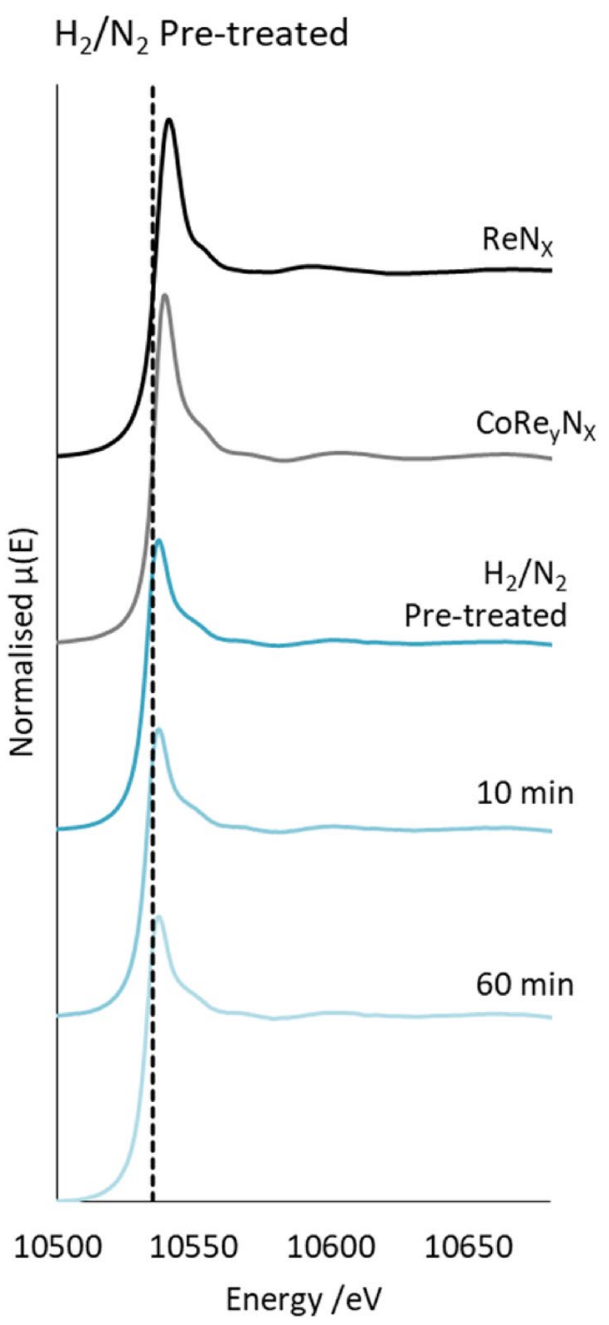

bonds will be better visualized at the element of low concentration in bimetallic phases [30]. However, due to rhenium being a heavy absorber optimising the dilution for XAS data collection was challenging, which in turn led to in situ cobalt data being of reduced quality. Another challenge in this study is obtaining reliable information about rhenium as a backscatterer due to the fact that a large part of the EXAFS signal lies in the high k-region, and the data in this study utilises a k-window of 3.5-9.5 $\AA^{-1}$ as the resolution beyond this value is limited by the in situ conditions.

Results from EXAFS analysis of references prepared by ammonolysis $\left(\mathrm{CoRe}_{\mathrm{y}} \mathrm{N}_{\mathrm{x}}, \mathrm{CoN}_{\mathrm{x}}\right.$ and $\left.\mathrm{ReN}_{\mathrm{x}}\right)$ are shown in Table 1 and Figure S.2 confirming that the process has led to the reduction to the metallic state in all three samples. Bimetallic mixing is confirmed for $\operatorname{CoRe}_{\mathrm{y}} \mathrm{N}_{\mathrm{x}}$ where coordination numbers of 4.6 for $\mathrm{Co}-\mathrm{Co}$ and 2.0 for $\mathrm{Co}-\mathrm{Re}$ are found at the cobalt edge, while average coordination numbers at the rhenium edge are 3.1 for $\mathrm{Re}-\mathrm{Re}$ and 3.0 for $\mathrm{Re}-\mathrm{Co}$. The bond-distance obtained for the $\mathrm{Co}-\mathrm{Co}$ bond in $\mathrm{CoRe}_{\mathrm{y}} \mathrm{N}_{\mathrm{x}}$ is $2.47 \AA$, which is slightly shorter than that obtained for the Co-foil (2.49 $\AA$ ), and the Re-Re bond length is $2.65 \AA$, which is shorter than that of Re-foil $(2.74 \AA$ ). From refinements, the $\mathrm{Co}-\mathrm{Re}$ bond length is $2.66 \AA$, while the corresponding Re-Co bond length at the rhenium edge is $2.57 \AA$. Shorter Re-Re bonds were also reported by $\mathrm{R} \emptyset n n i n g$ et al. for the $\mathrm{Co}-\mathrm{Re} / \mathrm{Al}_{2} \mathrm{O}_{3}$ system where, similar to our findings, they found the Re-Co bond length to be $2.54 \AA$ [15]. These numbers do in fact confirm bimetallic Co-Re mixing occurs in the sample, however as relatively high multiplicity $\mathrm{Co}-\mathrm{Co}$ and $\mathrm{Re}-\mathrm{Re}$ absorption pairs are found during refinements, one cannot exclude the possibility that pure Co and Re phases occur in the sample. Nitride formation, suggested by the partially oxidised rhenium from XANES for this sample, is confirmed by a Re-N shell at $1.76 \AA$. The low average $\mathrm{Re}-\mathrm{N}$ multiplicity of 0.4 and high $\mathrm{Re}-\mathrm{Re} / \mathrm{Co}$ coordination suggests there is still a large degree of metallic rhenium in this sample. A Re-N shell with average coordination of 0.6 is also found in the $\operatorname{ReN}_{\mathrm{x}}$ sample at $1.79 \AA$, in addition to the Re-Re shell at $2.67 \AA$. For the $\mathrm{CoN}_{\mathrm{x}}$ sample, only the Co-Co shell at $2.50 \AA$ with an average coordination of 4 is found in the refinement. 
EXAFS of $\mathrm{CoRe}_{1.6}$ after the two different pre-treatments clearly confirms that the presence of nitrogen during pre-treatment is a prerequisite for extensive bimetallic Co-Re mixing in $\mathrm{CoRe}_{1.6}$ (Table 3). While there are clear similarities in the EXAFS and Fourier Transform spectra at the rhenium edge (Fig. 7), there are clear differences in the cobalt EXAFS (Fig. 6). Cobalt, being the minor constituent in the sample, is the element which would be more sensitive to the degree of mixing. A large degree of Co-Re bimetallic mixing is observed in $\mathrm{CoRe}_{1.6}$ after pretreatment in $75 \% \mathrm{H}_{2}$ in $\mathrm{N}_{2}$, yielding coordination numbers of 3.2 for Co-Re and 3 for Re-Co at $2.51 \AA$. As observed for the post-ammonolysis samples, $\mathrm{CoRe}_{1.6}$ also exhibits Co-Co $(1.7$, at $2.45 \AA)$ and $\operatorname{Re}-\operatorname{Re}(5$, at $2.71 \AA$ ) backscattering pairs, suggesting pure cobalt and rhenium phases are also present. It is worth noting that the lack of second or third metal-metal scattering shells in these samples indicates a high degree of disorder in the system. Typically a second Re-metal distance is found at $3.56 \AA$ in bulk rhenium, which is absent in the $\mathrm{CoRe}_{1.6}$ system. This again is reflected in the XRD patterns (Figure S.5), which show a degree of amorphous background. It should be noted that attempts to introduce a $\mathrm{Re}-\mathrm{N}$ shell at low $\mathrm{R}$-value led to a decrease in fit-factor. Reasonable fit-values could not be obtained and the shell was therefore omitted.
For $\mathrm{CoRe}_{1.6}$ pre-treated in $75 \% \mathrm{H}_{2}$ in $\mathrm{Ar}$, attempts to introduce a $\mathrm{Co}-\mathrm{Re}$ coordination shell were unsuccessful, yielding only a Co-Co shell at $2.46 \AA$ with average coordination number of 9. At the rhenium edge, a Re-Co shell could be fitted, with average coordination of 1.7 at $2.51 \AA$. The major contribution to the signal is the Re-Re shell at $2.73 \AA$ with average coordination number of 7 . Clearly, the degree of mixing is greatly influenced by the pre-treatment, as the presence of nitrogen ensures bimetallic Co-Re pair formation. Average coordination numbers for the two pretreatments of $\mathrm{CoRe}_{1.6}$ are displayed in Fig. 8.

\subsection{Structural Changes During Ammonia Synthesis}

Following pre-treatment, $\mathrm{CoRe}_{1.6}$ was cooled to $400{ }^{\circ} \mathrm{C}$ where ammonia synthesis was carried out for $2 \mathrm{~h}$ in $75 \% \mathrm{H}_{2}$ in $\mathrm{N}_{2}$. The mass spectrometer (MS) signal is shown in Fig. 9, confirming the 20 min lag-time before ammonia production starts for the sample pre-treated in $\mathrm{H}_{2} / \mathrm{Ar}$, as has already been reported [9]. For CoRe $\mathrm{C}_{1.6}$ pre-treated in $\mathrm{H}_{2} / \mathrm{N}_{2}$ (reaction gas) ammonia production starts immediately. At this stage, as we have already established that the two pre-treatments affect the degree of Co-Re mixing and it is of interest to establish whether the observed lag-time can be explained by structural changes observable in in situ XAS. Following
Table 3 EXAFS least squares refinements of $\mathrm{CoRe}_{1.6}$ after $2 \mathrm{~h}$ pre-treatment at $600{ }^{\circ} \mathrm{C}$ in either $\mathrm{H}_{2} / \mathrm{N}_{2}$ or $\mathrm{H}_{2} / \mathrm{Ar}$ and during ammonia synthesis at $400{ }^{\circ} \mathrm{C}$ for both Co K-edge and $\mathrm{Re} \mathrm{L}_{\mathrm{III}}{ }^{-}$ edge from in situ XAS (AFAC transferred from Co-foil $=0.79$ and Re-foil $=0.8$ )

\begin{tabular}{|c|c|c|c|c|c|c|c|}
\hline Sample & Shell & $\mathrm{N}$ & $\mathrm{R}(\AA)$ & $2 \sigma^{2}\left(\AA^{2}\right)$ & $\mathrm{E}_{\mathrm{F}}(\mathrm{eV})$ & $\mathrm{R}(\%)$ & $\Delta \mathrm{k}$ \\
\hline \multirow[t]{4}{*}{$\mathrm{CoRe}_{1.6} \mathrm{H}_{2} / \mathrm{N}_{2} 600{ }^{\circ} \mathrm{C}$} & $\mathrm{Co}-\mathrm{Co}$ & $1.7(6)$ & $2.45(1)$ & $0.011(7)$ & $-6.3(8)$ & 39 & $2-8.5$ \\
\hline & $\mathrm{Co}-\mathrm{Re}$ & $3.2(9)$ & $2.51(1)$ & $0.020(6)$ & & & \\
\hline & $\mathrm{Re}-\mathrm{Co}$ & $3(1)$ & $2.51(2)$ & $0.042(9)$ & $-7(2)$ & 49 & $3.5-9.5$ \\
\hline & $\mathrm{Re}-\mathrm{Re}$ & $5(3)$ & 2.71(3) & $0.05(2)$ & & & \\
\hline \multirow[t]{3}{*}{$\mathrm{CoRe}_{1.6} \mathrm{H}_{2} / \mathrm{Ar} 600^{\circ} \mathrm{C}$} & $\mathrm{Co}-\mathrm{Co}$ & $9(2)$ & $2.46(1)$ & $0.049(5)$ & $-3(1)$ & 36 & $2-8.5$ \\
\hline & $\mathrm{Re}-\mathrm{Co}$ & $1.7(8)$ & $2.51(1)$ & $0.031(9)$ & $-9(1)$ & 47 & $3.5-9.5$ \\
\hline & $\mathrm{Re}-\mathrm{Re}$ & $7(3)$ & $2.73(1)$ & $0.05(1)$ & & & \\
\hline \multirow[t]{4}{*}{$\mathrm{H}_{2} / \mathrm{N}_{2} \mathrm{PT} 10 \mathrm{~min}$} & $\mathrm{Co}-\mathrm{Co}$ & $5(1)$ & $2.47(1)$ & $0.029(5)$ & $-6.1(8)$ & 29 & $2-8.5$ \\
\hline & $\mathrm{Co}-\mathrm{Re}$ & $2.1(7)$ & $2.52(1)$ & $0.010(7)$ & & & \\
\hline & $\mathrm{Re}-\mathrm{Co}$ & $3(2)$ & $2.54(6)$ & $0.05(2)$ & $-7(2)$ & 45 & $3.5-9.5$ \\
\hline & $\mathrm{Re}-\mathrm{Re}$ & $4(1)$ & $2.66(1)$ & $0.027(7)$ & & & \\
\hline \multirow[t]{4}{*}{$\mathrm{H}_{2} / \mathrm{N}_{2}$ PT 60 min } & $\mathrm{Co}-\mathrm{Co}$ & $2.7(8)$ & $2.509(7)$ & $0.013(7)$ & $-4.0(8)$ & 37 & $2-8.5$ \\
\hline & $\mathrm{Co}-\mathrm{Re}$ & $2.7(7)$ & $2.486(8)$ & $0.005(5)$ & & & \\
\hline & $\mathrm{Re}-\mathrm{Co}$ & $0.9(6)$ & $2.48(1)$ & $0.013(9)$ & $-8(2)$ & 45 & $3.5-9.5$ \\
\hline & $\mathrm{Re}-\mathrm{Re}$ & $5(2)$ & $2.70(1)$ & $0.029(8)$ & & & \\
\hline \multirow[t]{3}{*}{$\mathrm{H}_{2} / \mathrm{Ar}$ PT 10 min } & $\mathrm{Co}-\mathrm{Co}$ & $5.4(9)$ & $2.460(9)$ & $0.026(4)$ & $-1(1)$ & 29 & $2-8.5$ \\
\hline & $\mathrm{Re}-\mathrm{Co}$ & $1.2(5)$ & $2.56(2)$ & $0.013(6)$ & $-9(1)$ & 42 & $3.5-9.5$ \\
\hline & $\mathrm{Re}-\mathrm{Re}$ & $5(2)$ & $2.68(1)$ & $0.030(8)$ & & & \\
\hline \multirow[t]{4}{*}{$\mathrm{H}_{2} / \mathrm{Ar}$ PT mins } & $\mathrm{Co}-\mathrm{Co}$ & $4.7(8)$ & $2.452(8)$ & $0.024(4)$ & $-1(1)$ & 29 & $2-8.5$ \\
\hline & $\mathrm{Co}-\mathrm{Re}$ & $2(2)$ & $2.62(8)$ & $0.07(5)$ & & & \\
\hline & $\mathrm{Re}-\mathrm{Co}$ & $0.7(3)$ & $2.531(9)$ & $0.002(6)$ & $-11(1)$ & 36 & $3.5-9.5$ \\
\hline & $\mathrm{Re}-\mathrm{Re}$ & $5(2)$ & $2.743(9)$ & $0.026(6)$ & & & \\
\hline
\end{tabular}

PT refers to pre-treatment and the times given correspond to reaction times under ammonia synthesis conditions 
Fig. 6 Experimental (line) and calculated (dotted line) $\mathrm{k}^{3}$-weighted EXAFS (left) and its Fourier Transform (right) for $\mathrm{CoRe}_{1.6}$ after pre-treatment in $\mathrm{H}_{2} / \mathrm{N}_{2}(\mathbf{a}-\mathbf{b})$ and $\mathrm{H}_{2} / \mathrm{Ar}(\mathbf{c}-\mathbf{d})$ for the Co K-edge
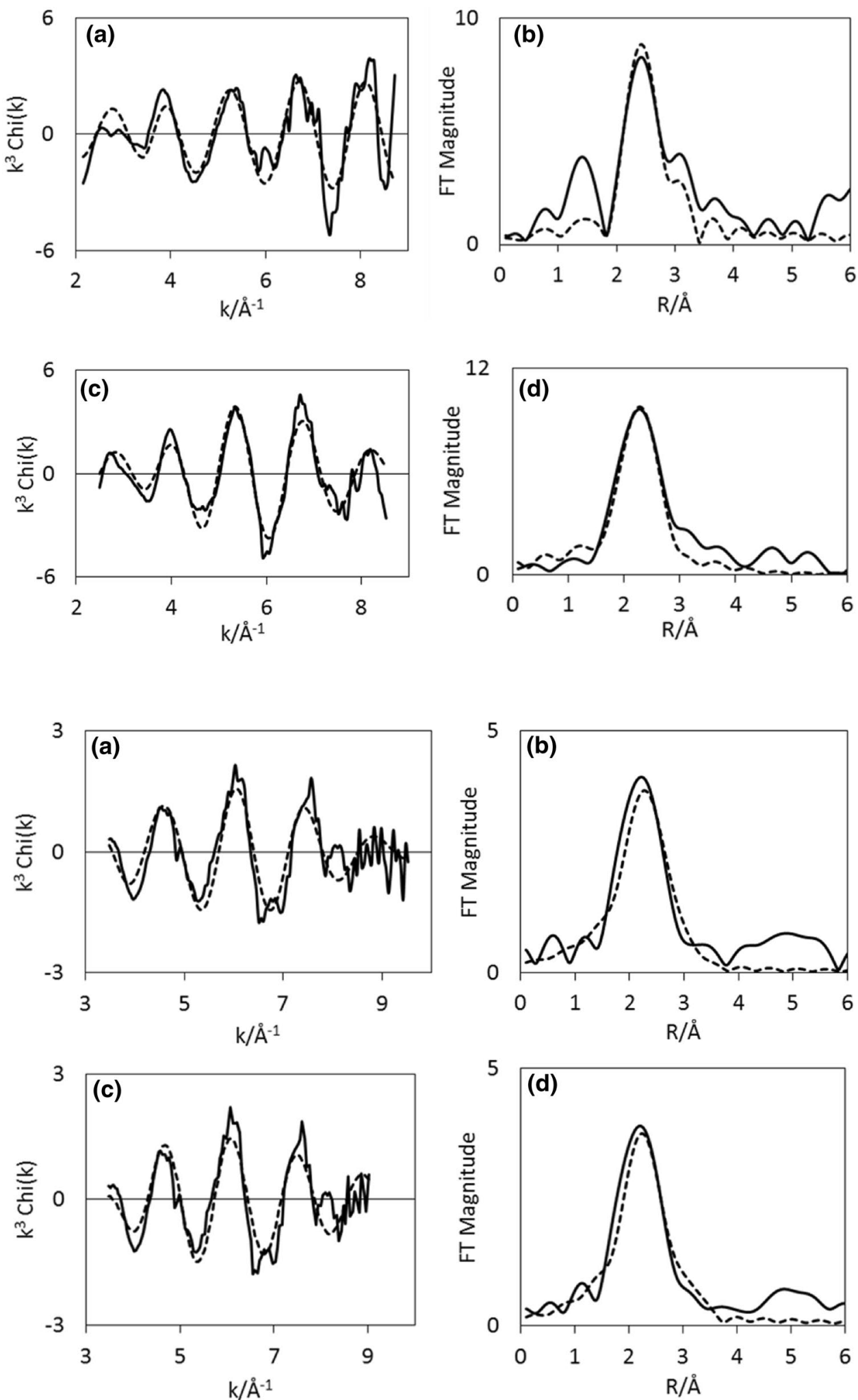

pre-treatment, $\mathrm{CoRe}_{1.6}$ was cooled to $400{ }^{\circ} \mathrm{C}$ where ammonia synthesis was carried out for $2 \mathrm{~h}$ in $75 \% \mathrm{H}_{2}$ in $\mathrm{N}_{2}$.

The normalised XANES at both edges taken after 10 and $60 \mathrm{~min}$ under ammonia synthesis reaction conditions are displayed in Figs. 4 and 5. No changes appear to occur in the cobalt XANES when compared to the spectra after the pre-treatment. The XANES are also similar independently of pre-treatment. Interestingly, when examining 
Fig. 8 Average coordination numbers $(\mathrm{N})$ from EXAFS analysis for $\mathrm{CoRe}_{1.6}$ after $120 \mathrm{~min}$ pre-treatment at $600{ }^{\circ} \mathrm{C}$ in $\mathrm{H}_{2} /$ $\mathrm{N}_{2}$ (left) or $\mathrm{H}_{2} / \mathrm{Ar}$ (right) for $\mathrm{Co}$ K-edge and Re- $\mathrm{L}_{\text {III }}$ edge
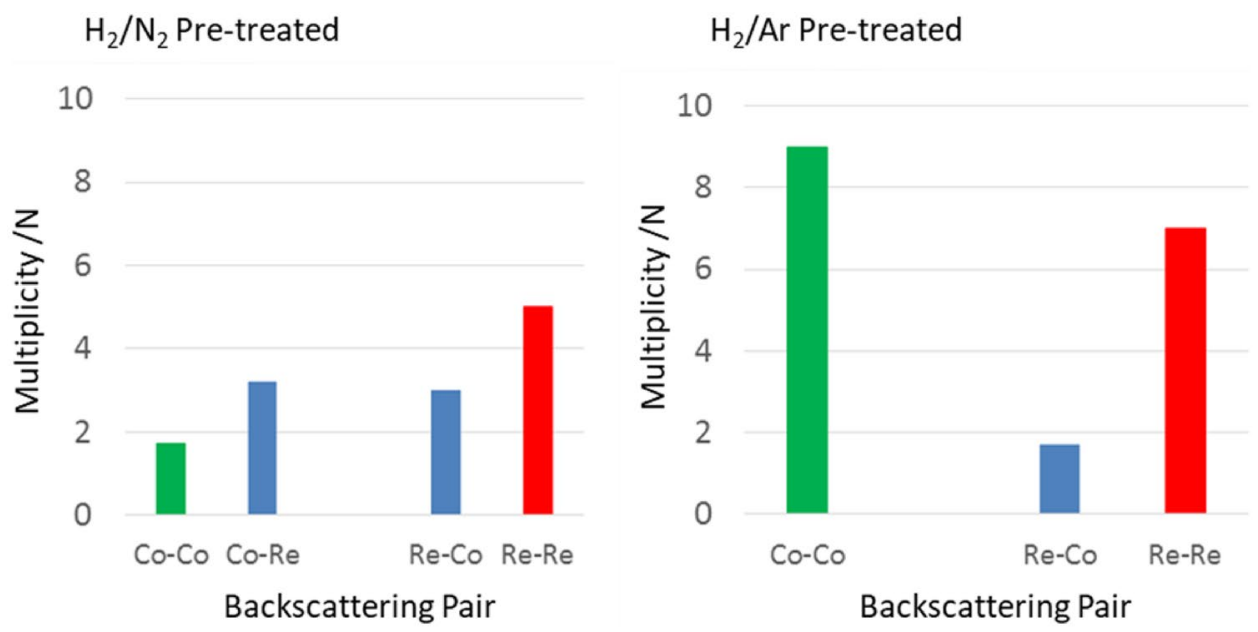

Fig. 9 Online ion current signals showing ammonia production over time $\left(\mathrm{NH}_{3}=\right.$ red, $\mathrm{N}_{2}=$ green and $\mathrm{H}_{2}=$ blue) from mass spectrometry during in situ XAS/XRD data collection for $\mathrm{CoRe}_{1.6}$ at $400{ }^{\circ} \mathrm{C}$ in $75 \% \mathrm{H}_{2}$ in $\mathrm{N}_{2}$ reaction gas. The ammonia signal confirms the occurrence of a lag-time following $\mathrm{H}_{2} / \mathrm{Ar}$ pre-treatment as observed during catalytic measurements

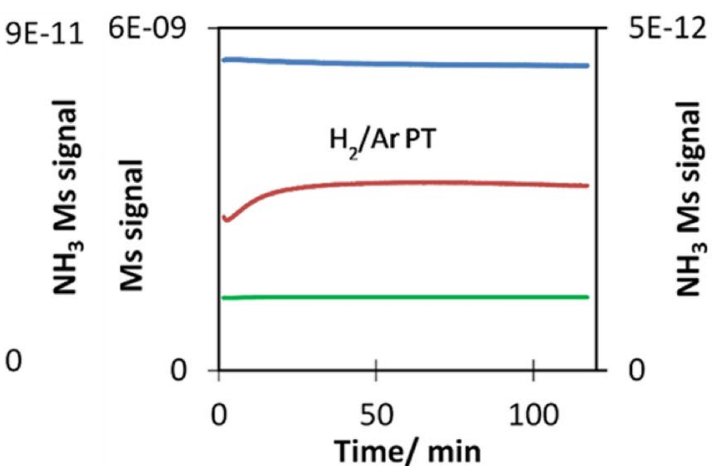

the rhenium normalised XANES, it is clear that the white line of the $\mathrm{CoRe}_{1.6}$ sample pre-treated in $\mathrm{H}_{2}$ /Ar shows an increase in intensity 10 and $60 \mathrm{~min}$ into ammonia synthesis. The intensity of the white line for Re $\mathrm{L}_{\mathrm{III}}$-edge XANES is caused by the transition from $2 p_{3 / 2}$ to $5 d$, and typically the higher the oxidation state, the higher the white line. It is often regarded as difficult to extract quantitative information from variations in white line intensity for the rhenium $\mathrm{L}_{\mathrm{III}}$-edge. However it seems clear that the observed change in electronic state of the Re species is not correlated with a similar change in the Co species. Hence, the change seems to occur in a pure Re-phase, and corresponds to the material becoming active for ammonia synthesis. The observed increase in intensity could possibly be an effect of partial oxidation of rhenium. However attempts to fit a Re-N shell for this sample were not successful.

Results from EXAFS refinements (Table 3), show that the $\mathrm{Co}-\mathrm{Re}$ mixing observed in the sample pre-treated in $\mathrm{H}_{2} /$ $\mathrm{N}_{2}$ also remains during ammonia synthesis at $400{ }^{\circ} \mathrm{C}$. After $10 \mathrm{~min} 2.1 \mathrm{Co}-\mathrm{Re}$ distances are fitted at $2.52 \AA$, and corresponding three Re-Co distances are found at $2.54 \AA$ at the rhenium edge. After $60 \mathrm{~min}, 2.7 \mathrm{Co}-\mathrm{Re}$ distances remain at $2.48 \AA$, but at the rhenium edge only 0.9 is found at $2.48 \AA$. This could suggest some reorganisation of the nanostructure of the material and possible segregation of species occurs during reaction. There is a small shortening of the Co- $\mathrm{Re} /$ $\mathrm{Re}-\mathrm{Co}$ average distance. During time on stream, Co-Co is reduced from 5 to 2.7 in multiplicity, and this shell undergoes an elongation from 2.47 to $2.51 \AA$. Similarly, the Re-Re bond is slightly elongated from 2.66 to $2.70 \AA$, but remains at 4-5 in average coordination number during the process. Experimental and calculated EXAFS and Fourier Transforms for $\mathrm{CoRe}_{1.6}$ following pre-treatment in $\mathrm{H}_{2} / \mathrm{N}_{2}$ after 10 and 60 min of reaction time show only minor changes (Figs. 10, 11).

By comparison, experimental and calculated EXAFS spectra of the sample pre-treated in $\mathrm{H}_{2} / \mathrm{Ar}$ are shown in Figs. 12 and 13, and while there appears to be only small changes at the cobalt edge, the changes in the local rhenium surroundings are more apparent. The lack of $\mathrm{Co}-\mathrm{Re}$ mixing is still present following the pre-treatment in $\mathrm{H}_{2} / \mathrm{Ar}$ and during subsequent $\mathrm{H}_{2} / \mathrm{N}_{2}$ reaction at $400{ }^{\circ} \mathrm{C}$, with only $5.4 \mathrm{Co}-\mathrm{Co}$ distances being fitted at $2.46 \AA$ after $10 \mathrm{~min}$ of reaction at the cobalt edge (Fig. 14). After $60 \mathrm{~min}$, the 4.6 Co-Co distances remain at $2.45 \AA$, but adding a second Co-Re contribution at $2.62 \AA$ with average coordination of 2 improves the fit. However, the uncertainties and specifically the Debye-Waller factor are questionable suggesting 
Fig. 10 Experimental (line) and calculated (dotted line) $\mathrm{k}^{3}$-weighted EXAFS (left) and its Fourier Transform (right) for $\mathrm{CoRe}_{1.6}$ after pre-treatment in $\mathrm{H}_{2} / \mathrm{N}_{2}$ and after time on stream $10 \mathrm{~min}(\mathbf{a}-\mathbf{b})$ and $60 \mathrm{~min}(\mathbf{c}-\mathbf{d})$ in $\mathrm{H}_{2} / \mathrm{N}_{2}$ at $400{ }^{\circ} \mathrm{C}$ for the Co K-edge
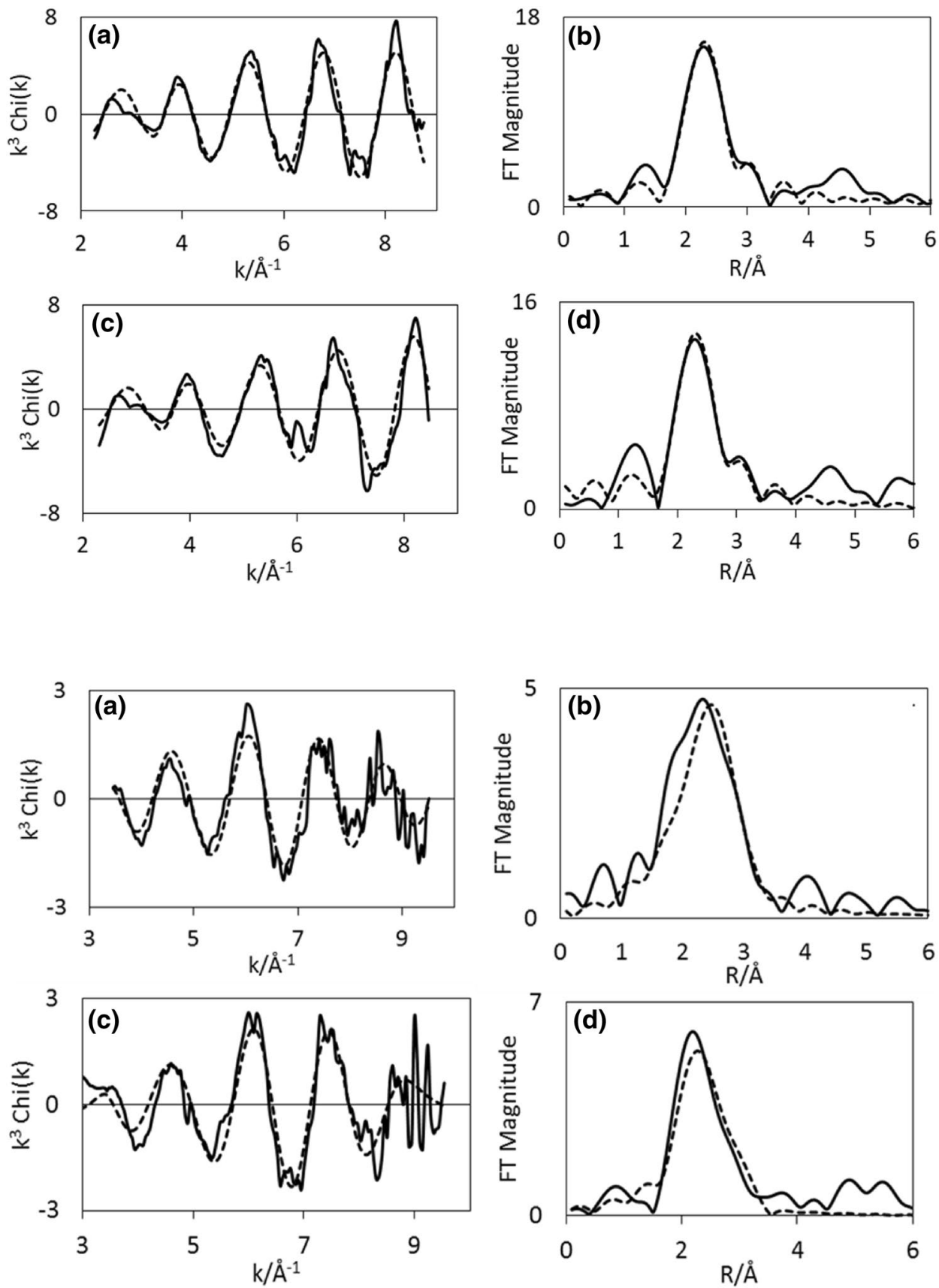

the major contribution is still in fact only Co-Co. At the rhenium edge, the major contribution is still $\mathrm{Re}-\mathrm{Re}$ with average coordination of 5 during reaction, although the bond elongates from 2.68 to $2.73 \AA$. A low coordinated (1.2 and 0.7) Re-Co interaction remains at 2.56-2.53 during the reaction. Refinements reveal the $\mathrm{Co}-\mathrm{Re}$ mixing to be irreversible, but as the $\mathrm{Re}-\mathrm{Co}$ shell is present, some mixing is obtained also after pre-treatment in $\mathrm{H}_{2} / \mathrm{Ar}$. A comparison of the Fourier Transformed EXAFS spectra for the pre-treatment and time on stream is shown in Figures S.6 and S.7.

\section{Discussion}

\subsection{Effect of Pre-treatment on the Phases Formed in Cobalt Rhenium}

The in situ XAS results can be summarised as follows; the presence of $\mathrm{Co}-\mathrm{Co}, \mathrm{Co}-\mathrm{Re}$ and $\mathrm{Re}-\mathrm{Re}$ interatomic distances indicate there to be a mixture of phases in the $\mathrm{CoRe}_{1.6}$ system during ammonia synthesis, with both Co-Re bimetallic species, and monometallic Re and Cospecies being evident. The lack of a second metal-metal 
Fig. 12 Experimental (line) and calculated (dotted line) $\mathrm{k}^{3}$-weighted EXAFS (left) and its Fourier Transform (right) for $\mathrm{CoRe}_{1.6}$ after pre-treatment in $\mathrm{H}_{2} / \mathrm{Ar}$ and after time on stream $10 \mathrm{~min}(\mathbf{a}-\mathbf{b})$ and $60 \mathrm{~min}(\mathbf{c}-\mathbf{d})$ in $\mathrm{H}_{2} / \mathrm{N}_{2}$ at $400{ }^{\circ} \mathrm{C}$ at the $\mathrm{Co}$ K-edge
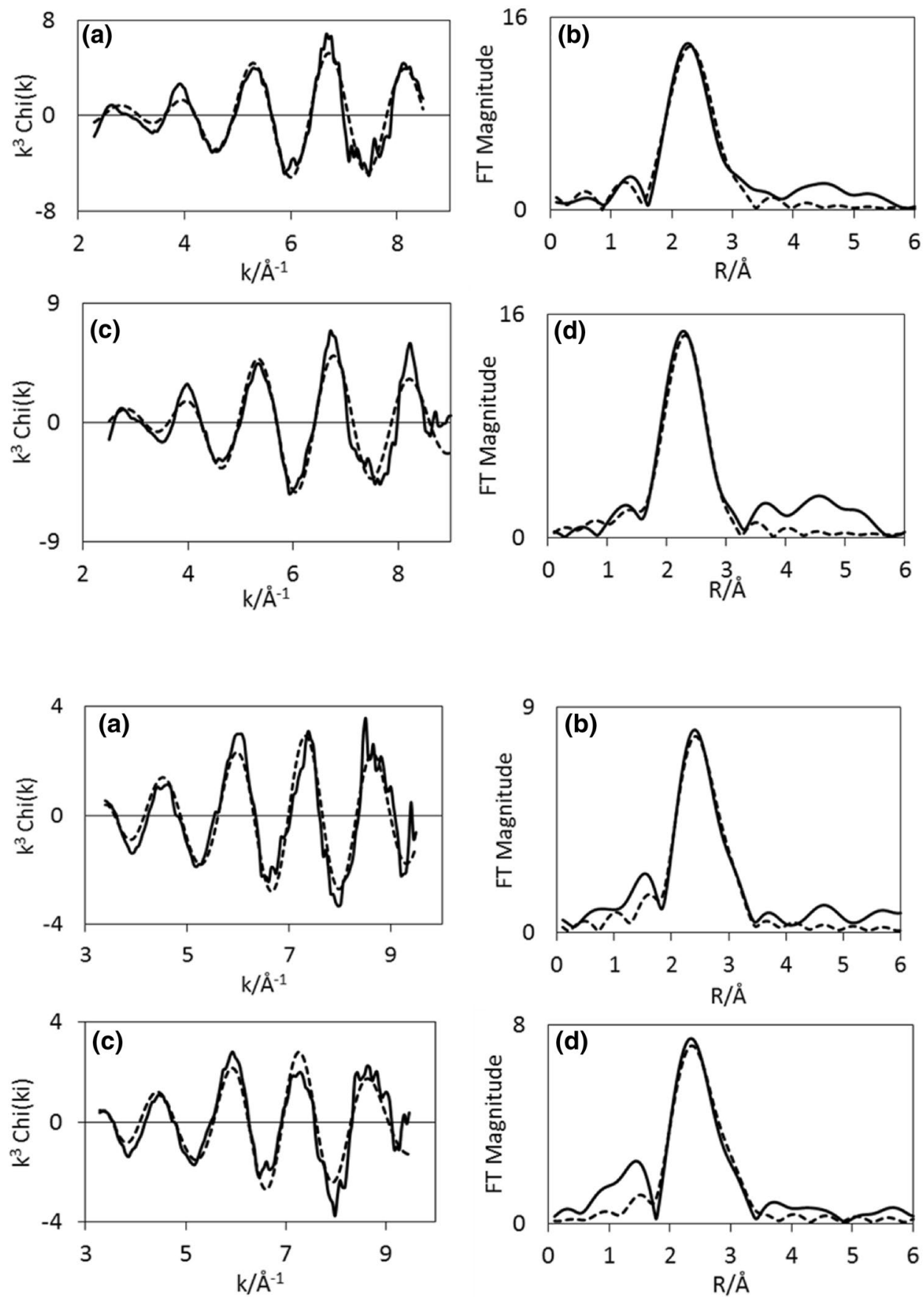

absorption shell in the analysis of both Co K-edge and Re $\mathrm{L}_{\mathrm{III}}$-edge EXAFS indicate a high degree of disorder in the major phase. The fraction of bimetallic phase has been calculated after the method of Shibata et al. [32] based on the average coordination number $(\mathrm{N})$ of $\mathrm{Re}-\mathrm{Co}$ and $\mathrm{Co}-\mathrm{Re}$ shells and the total coordination number $\left(\mathrm{N}_{\mathrm{Re}-\mathrm{Re}}+\mathrm{N}_{\mathrm{Re}-\mathrm{Co}}\right.$, $\mathrm{N}_{\mathrm{Co}-\mathrm{Co}}+\mathrm{N}_{\mathrm{Co}-\mathrm{Re}}$ ) to follow the amount of bimetallic phase, as shown in Fig. 15. After pre-treatment in $\mathrm{H}_{2} \mathrm{~N}_{2}$, the major contribution is the $\mathrm{Co}-\mathrm{Re}$ bimetallic particles and pure $\mathrm{Re}$-species with some Co-species also present.
After pre-treatment in $\mathrm{H}_{2} / \mathrm{Ar}$ the major contribution is Co and Re phases, with only a very small presence of $\mathrm{Co}-\mathrm{Re}$ bimetallic phase. The higher refined sum of first shell multiplicities for $\mathrm{CoRe}_{1.6}$ after pre-treatment in $\mathrm{H}_{2} /$ Ar also indicates a larger particle size for this catalyst. This is in accordance with previous findings on supported $\mathrm{Co} /$ Re systems where the role of rhenium is to prevent cobalt agglomeration via promotion of reduction at lower temperatures [10]. Clearly, the latter is true for the $\mathrm{CoRe}_{1.6}$ system for pre-treatments in both $\mathrm{H}_{2} / \mathrm{N}_{2}$ and $\mathrm{H}_{2} / \mathrm{Ar}$, as cobalt 
Fig. 14 Average coordination numbers $(\mathrm{N})$ from EXAFS analysis for $\mathrm{CoRe}_{1.6}$ during treatment at $600{ }^{\circ} \mathrm{C}$ in $\mathrm{H}_{2} / \mathrm{N}_{2}$ $\mathrm{K}$-edge and the $\operatorname{Re} \mathrm{L}_{\mathrm{III}}$-edge ammonia synthesis after pre(left) or $\mathrm{H}_{2} / \mathrm{Ar}$ (right) at the $\mathrm{Co}$
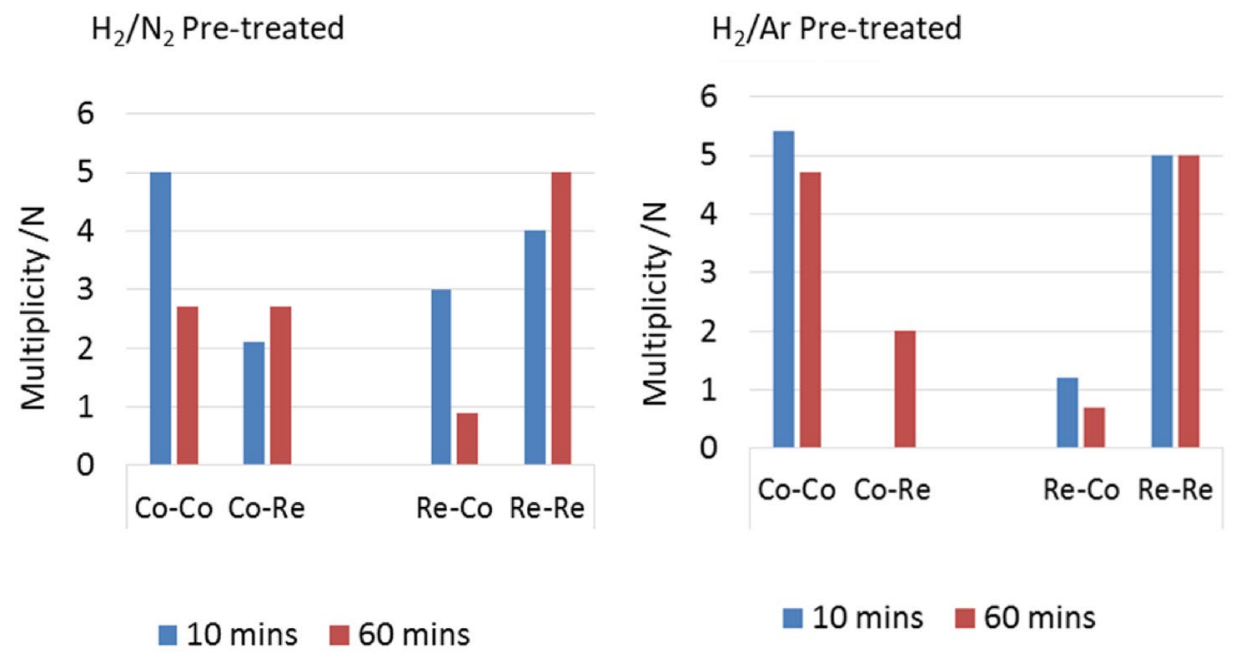

Fig. 15 The fraction of bimetallic phase determined at the $\mathrm{Re}$ $\mathrm{L}_{\mathrm{III}}$-edge and Co K-edge

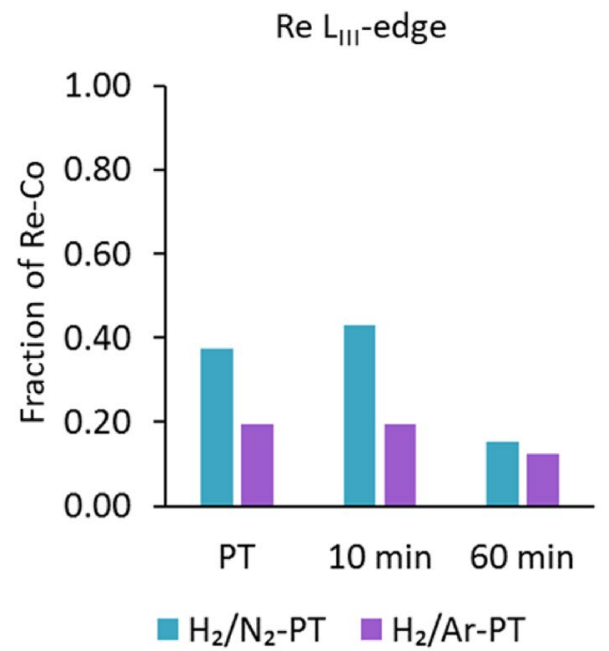

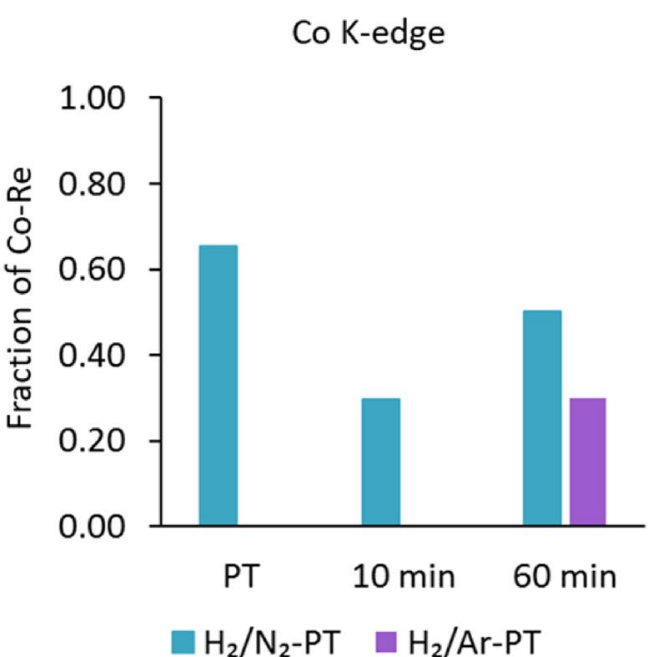

undergoes complete reduction starting at a temperature as low as $250{ }^{\circ} \mathrm{C}$. However, the choice of pre-treatment atmosphere clearly affects the $\mathrm{Co}-\mathrm{Re}$ alloying process, which is significantly inhibited in $\mathrm{H}_{2} / \mathrm{Ar}$.

\subsection{Can In Situ-XAS Reveal Mechanistic Aspects of Cobalt Rhenium During Ammonia Synthesis?}

It is assumed that the activity of cobalt rhenium for ammonia synthesis is governed by activation of $\mathrm{N}_{2}$ by the active phase, and that the activity of the sample pre-treated in $\mathrm{H}_{2} /$ $\mathrm{N}_{2}$ is superior to that pre-treated in $\mathrm{H}_{2} / \mathrm{Ar}$, even after the lag. From the in situ EXAFS analysis it is clear that the sample pre-treated in $\mathrm{H}_{2} / \mathrm{N}_{2}$ has better mixture of the Co-Re pair, or consists of more of the bimetallic phase. Significant nitride formation as a result of $\mathrm{H}_{2} / \mathrm{N}_{2}$ pre-treatment can also be excluded, as a $\mathrm{Re}-\mathrm{N} / \mathrm{Co}-\mathrm{N}$ shell was not found in EXAFS refinements at any stage. This is further confirmed by XANES and variations in $\mathrm{E}_{0}$, which revealed that both
$\mathrm{Co}$ and $\mathrm{Re}$ are completely reduced at all stages. This also correlates with the denitridation of the $\mathrm{N}_{2} / \mathrm{H}_{2}$ pre-treated $\mathrm{CoRe}_{1.6}$ sample measuring the ammonia production in $\mathrm{H}_{2} /$ Ar at $400{ }^{\circ} \mathrm{C}$ (Figure S.3). Assuming nitrogen is stored in the material one would expect ammonia production to occur for some time, however this is not observed suggesting a surface reaction mechanism. It should be noted that during fitting procedures, attempts were made to add both a $\mathrm{Re}-\mathrm{N}$ and Co-N shell around 1.75-1.80 $\AA$ to the $\mathrm{CoRe}_{1.6}$ at each stage of reaction. For the sample treated in $\mathrm{H}_{2} / \mathrm{N}_{2}$ addition of such a shell at the rhenium edge lowered the R-factor by up to $10 \%$, but very low multiplicities and/or negative Debye-Waller factors were obtained. Such a reduction of the R-factor was also observed for $\mathrm{CoRe}_{1.6}$ for both pre-treatments after $60 \mathrm{~min}$ in reaction gas. It is possible that a signal in this lower R-range stems from nitrogen inclusion species $\left(\mathrm{M}-\mathrm{N}_{\mathrm{in}}\right)$ in the metal phase or traces of surface nitrogen species $\left(\mathrm{M}-\mathrm{N}_{\text {surf }}\right)$, however we believe the average coordination number could be limited by the particle size of the $\mathrm{CoRe}_{1.6}$ phase. 


\section{Conclusions}

A CoRe $e_{1.6}$ catalyst active for ammonia production at $400{ }^{\circ} \mathrm{C}$ and ambient pressure following a reduction step at $600{ }^{\circ} \mathrm{C}$ in either $\mathrm{H}_{2} / \mathrm{N}_{2}$ or $\mathrm{H}_{2} / \mathrm{Ar}$ was investigated in situ using XAS and XRD. Specifically the reduction profiles were targeted depending on pre-treatment mixture and the nature of the active species during ammonia synthesis reaction conditions analysed. While both pre-treatments render the material active, the $\mathrm{H}_{2} /$ Ar reduction step results in a 20 min lagtime also observed during in situ measurements. Rhenium XANES reveal a synergistic effect and similar reduction profiles for both pre-treatments, with Co initiating reduction and Re being near completely reduced within the $300-375{ }^{\circ} \mathrm{C}$ interval. The only observable difference is in the cobalt XANES, where slight differences are observed between the two pre-treatments as the profile of the $\mathrm{H}_{2} / \mathrm{Ar}$ pre-treatments initiates at a lower temperature. The two pretreatments result in the formation of Co-Re bimetallic alloys and pure $\mathrm{Co}$ and Re monometallic phases. The bimetallic Co-Re phase is the major component following pre-reduction in $\mathrm{H}_{2} / \mathrm{N}_{2}$ while the latter is the major component in the active material following $\mathrm{H}_{2} / \mathrm{Ar}$ pre-treatment. Clearly the presence of nitrogen in the reduction step promotes a high degree of bimetallic Co-Re mixing confirmed by $\mathrm{Co}-\mathrm{Re} /$ Re-Co absorption shells at both edges. EXAFS confirms restructuring of the pure $\mathrm{Re}$ and Co phases following $\mathrm{H}_{2} / \mathrm{Ar}$ pre-treatment only after 60 min during time on stream in $\mathrm{H}_{2} /$ $\mathrm{N}_{2}$. Formation of the bimetallic Co-Re phase coincides with the observed lag-time both during catalytic experiments and in situ conditions.

Acknowledgements We acknowledge the Norwegian University of Science and Technology and the Norwegian Research Council for grants supporting the Swiss-Norwegian Beamlines (SNBL) and the Anders Jahre fund for promotion of science. The assistance of beamline scientists M. Brunelli and W. van Beek is very much appreciated. We are also grateful to the EPSRC for supporting this work through grants EP/L02537X/1 and EP/J018384/1.

Open Access This article is distributed under the terms of the Creative Commons Attribution 4.0 International License (http://creativeco mmons.org/licenses/by/4.0/), which permits unrestricted use, distribution, and reproduction in any medium, provided you give appropriate credit to the original author(s) and the source, provide a link to the Creative Commons license, and indicate if changes were made.

\section{References}

1. Bion N, Can F, Cook J, Hargreaves JSJ, Hector AL, Levason W, McFarlane AR, Richard M, Sardar K (2015) Appl Catal A: Gen 504:44
2. Hayashi F, Kitano M, Yokoyama T, Hara M, Hosono H (2014) ChemCatChem 6:1317

3. Jacobsen CJH, Dahl S, Clausen BS, Bahn S, Logadottir A, Nørskov JK (2001) J Am Chem Soc 123:8404

4. Kojima R, Aika K-I (2001) Appl Catal A: Gen 218:121

5. McKay D, Hargreaves JSJ, Rico JL, Rivera JL, Sun XL (2008) J Solid State Chem 181:325

6. Schlögl R (2003) Angew Chem Int Ed 42:2004

7. Kojima R, Aika K-I (2001) Appl Catal A: Gen 209:317

8. Alexander AM, Hargreaves JSJ, Mitchell C (2013) Top Catal 56:1963

9. McAulay K, Hargreaves JSJ, McFarlane AR, Price DJ, Spencer NA, Bion N, Can F, Richard M, Greer HF, Zhou WZ (2015) Catal Commun 68:53

10. Bazin D, John L (2002) Catal Lett 84:169 182

11. Das TK, Jacobs G, Patterson PM, Conner WA, Li J, Davis BH (2003) Fuel 82:805

12. Jacobs G, Chaney JA, Patterson PM, Das TK, Davis BH (2004) Appl Catal A: Gen 264:203

13. Jacobs G, Ji Y, Davis BH, Cronauer D, Kropf AJ, Marshall CL (2007) Appl Catal A 333:177

14. Rønning M, Tsakoumis NE, Voronov A, Johnsen RE, Norby P, van Beek W, Borg Ø, Rytter E, Holmen A (2010) Catal Today 155:289

15. Rønning M, Nicholson DG, Holmen A (2001) Catal Lett 72:141

16. Koningsberger DC, Mojet BL, van Dorssen GE, Ramaker DE (2000) Top Catal 10:143

17. Voronov A, Tsakoumis NE, Hammer N, van Beek W, Emerich H, Rønning M (2014) Catal Today 229:23

18. Bakken V, Bergene E, Rytter E, Swang O (2010) Catal Lett 135:21

19. Tsakoumis NE, Voronov A, Rønning M, Beek WV, Borg Ø, Rytter E, Holmen A (2012) J Catal 291:138

20. Ravel B, Newville M (2005) J Synchrotron Radiat 12:537

21. Tomic S, Searle BG, Wander A, Harrison NM, Dent AJ, Mosselmans JFW, Inglesfield JE, CCLRC Technical Report 2005, Council for the Central Laboratory of the Research Councils, UK

22. Romão CC, Kühn FE, Herrmann WA (1997) Chem Rev 97:3197

23. Crumpton TE, Mosselmans JFW, Greaves C (2005) J Mater Chem $15: 164$

24. Schanke D, Vada S, Blekkan EA, Hilmen AM, Hoff A, Holmen A (1995) J Catal 156:85

25. Steen Ev, Sewell GS, Makhothe RA, Micklethwaite C, Manstein H, de Lange M, O'Connor CT(1996) J Catal 162:220

26. Hilmen AM, Schanke D, Holmen A (1996) Catal Lett 38:143

27. Kumar N, Payzant EA, Jothimurugesan K, Spivey JJ (2011) Phys Chem Chem Phys 13:14735

28. Fung AS, Tooley PA, Kelley MJ, Koningsberger DC, Gates BC (1991) J Phys Chem 95:225

29. Sa J, Kartusch C, Makosch M, Paun C, van Bokhoven JA, Kleymenov E, Szlachetko J, Nachtegaal M, Manyar HG, Hardacre C (2011) Chem Commun 47:6590

30. Guczi L, Bazin D, Kovács I, Borkó L, Schay Z, Lynch J, Parent P, Lafon C, Stefler G, Koppány Z, Sajó I (2002) Top Catal 20:129

31. Frenkel AI, Machavariani VS, Rubshtein A, Rosenberg Y, Voronel A, Stern EA (2000) Phys Rev B 62:9364

32. Shibata T, Bunker BA, Zhang Z, Meisel D, Vardeman CF, Gezelter JD (2002) J Am Chem Soc 124:11989 